\title{
CORRELATOS EN IAS CONSTELACIONES SEMIÓTICAS DEL SOL Y DE LA LUNA EN LAS ÁREAS CENTRO Y SUR ANDINAS
}

\section{CORRESPONDENCE OF SEMIOTIC SUN AND MOON CONSTELLATIONS IN THE CENTRAL AND SOUTHERN ANDES}

Rodrigo Moulana ${ }^{A}$, María Catrlleo $^{B}$, Fellipe Hasler $^{c}$

El presente artículo analiza el correlato en las concepciones simbólicas del sol y de la luna en culturas de las áreas centro y sur andinas, como la inca, aymara y mapuche. $\mathrm{Al}$ respecto se destaca la existencia de homologías lingüísticas en las voces que designan a los astros y una concordancia en las representaciones sociales de estos, como integrantes de una familia divina. En el correlato de estas constelaciones semióticas se muestra una cotradición cultural en la que subyacen relaciones sociales de carácter histórico. Este análisis muestra el carácter preincaico de esta tradición compartida en las áreas centro y sur andinas.

Palabras clave: áreas centro y sur andinas, rasgos cotradicionales, semiótica, mapuche, sol y luna.

This paper analyzes the correspondence in symbolic concepts of the sun and moon in cultures of the Central and Southern Andes, such as the Inca, Aymara and Mapuche. In this regard, we show the existence of linguistic homologies in the voices designating celestial bodies, and a concordance in social representations of these entities as members of a divine family. The correlation of these semiotic constellations expresses cotraditional traits underpinned by historic cultural relations. This analysis shows the pre-Inka nature of this shared tradition in the Central and Southern Andes.

Keywords: Central and Southern Andes, cotraditional traits, semiotics, Mapuche, sun and moon.
El sol y la luna son objetos de atención ineludibles para los seres humanos y constituyen motivos privilegiados de sus elaboraciones culturales por su carácter dominante como referentes astronómicos y su relación con los ciclos naturales. La antropología emplea el concepto 'símbolos naturales' (Douglas 1996 [1970]) para designar la función semiótica que asumen los fenómenos del medio ambiente físico y biológico cuando se emplean como elementos significantes asociados a complejas tramas de sentido. El término es un oxímoron, como advierte Winzeler (2012), puesto que expone una contradicción lógica: los símbolos son constructos culturales, producidos socialmente, no entidades naturales. La propia noción de 'naturaleza' no tiene nada de natural, pues se trata de una categoría construida (Descola 2012), cuya extensión y presencia o no en los sistemas culturales varía de modo notorio. Allí donde los ojos occidentales ven entidades físicas otros pueblos identifican personas, ancestros o espíritus. Por lo mismo, el estudio de los 'símbolos naturales' nos permite registrar las estructuras de sentido distintivas de sus respectivas matrices de producción.

A Rodrigo Moulian, Instituto de Comunicación Social, Universidad Austral de Chile, Campus Isla Teja, Valdivia, E-mail: rmoulian@hotmail.com

B María Catrileo, Instituto de Lingüística y Literatura, Universidad Austral de Chile, Campus Isla Teja, Valdivia, E-mail: mcatrile@uach.cl

c Felipe Hasler, Departamento de Lingüística, Universidad de Chile, Campus Juan Gómez Millas, E-mail: keche.felipe@gmail.com 
No obstante, cuando los referentes que sirven de elementos significantes se encuentran regulados por principios extrasemióticos o participan de encadenamientos causales observables, estos resultan propensos a una lectura de base indexal (Peirce 1974). Con este término se distingue a las relaciones de significación que presuponen un vínculo 'natural', es decir, anterior a la semiosis, entre el elemento del plano de la expresión y el contenido. Es lo que ocurre, por ejemplo, entre el agua y la vida, en tanto se reconoce que la primera es una condición necesaria para la segunda. Este tipo de relaciones es una fuente potencial para órdenes de significados probabilísticamente convergentes, pero no universales, porque estas relaciones deben ser reconocidas, integradas en la cultura y socializadas, lo que no siempre ocurre del mismo modo.

En contraste, el predominio de formas de semiosis convencional, dominante en nuestra especie, es la fuente de la divergencia en los procesos de representación cultural. Ello ocurre tanto en el plano de las formas lingüísticas que designan a los referentes como de los significados que se les atribuyen. Por lo mismo, el estudio comparativo translingüístico de los símbolos naturales es una vía para el análisis de las relaciones interculturales. Dado que la producción de las representaciones asociadas a los símbolos naturales es un proceso cultural, la identificación de correlaciones en el registro translingüístico y transcultural -cuando estas muestran rasgos expresivos y representaciones compartidas- es un indicador de relaciones sociales históricamente labradas. Así ocurre con las denominaciones, concepciones y usos del sol y de la luna en las áreas centro y sur andinas, sensu Lumbreras (1981).

Havestadt (1883 [1777]) ha sido señero en advertir la existencia de homologías lingüísticas entre las lenguas quechua y mapuche, planteando el origen central andino de la voz antü, que designa al sol en mapundungun. Según el autor, esta habría sido adoptada a partir del comercio con los pueblos originarios peruanos. Guevara afirma que esta influencia se extiende al campo religioso, puesto que los incas difundieron hasta la Araucanía el culto al sol y a la luna. Al respecto, este investigador hipotetiza que la voz anchumallen designa a la 'mujer del sol' y plantea que "no sería aventurado sostener que esta representación refiere a la luna, cuyo culto debió pasar a Chile con el nombre del satélite, pues en quichua es quilla i en araucano cuyen" (Guevara 1911:231). En tanto, Lehmann-Nitsche (1919) advierte la identidad mítica de las representaciones sobre el sol y la luna entre los pueblos andinos del territorio comprendido por Perú, Bolivia y Chile, donde a estos astros se los tiene por esposos. Al igual que los autores mencionados, el etnólogo alemán explica esta situación como resultado de la influencia del incario sobre los pueblos australes.

En el presente artículo analizaremos las homologías lingüísticas y expondremos el correlato en las concepciones simbólicas existentes en torno a estos astros en las áreas centro y sur andinas. En contraste con los anteriores autores, argumentaremos que esto no se puede explicar como resultado de la influencia del Imperio inca.

\section{PERSPECTIVA TEÓRICO-METODOLÓGICA}

Desde la institucionalización de la antropología en Chile, el particularismo histórico y cultural ha sido la perspectiva predominante en los estudios sobre el pueblo mapuche. Durante casi diez años, nuestro propio trabajo de campo sobre las instituciones religiosas mapuche williche estuvo ceñido por esta perspectiva (Moulian \& Valdés 2001; Moulian 2005, 2008, 2012), hasta que se nos reveló el origen quechua del nombre de las congregaciones rituales que investigábamos (Moulian \& Espinoza 2015). Este antecedente modificó nuestra agenda de investigación y nos orientó hacia el estudio de las relaciones interculturales de los pueblos originarios del territorio andino.

Como reconocen Adán et al. (2016), el debate sobre la andinización del espacio centro y sur de Chile tiene larga data. Barros Arana (1884), desde el ejercicio de la historia; Guevara (1911), a partir de su experiencia de campo; y Patrón (1912), desde el análisis lingüístico, atribuyen al inca un rol civilizatorio sobre los pueblos de este territorio. No obstante, los datos disponibles respecto de la cronología y extensión territorial del Tawantinsuyo no son consistentes con este relato. El análisis de termoluminiscencia de piezas cerámicas incas en la zona central arroja un fechado de 1390 de nuestra era para la presencia cusqueña en este espacio (Cornejo 2014). En tanto, el límite meridional de los emplazamientos incas se sitúa en torno al río Maule, donde se localiza el último pucara del que se tenga registro (Stehberg 1976). Si bien es evidente que el desarrollo del Tawantinsuyo ha dejado su impronta en la cultura mapuche, resulta reductor constreñir la discusión de la andinización a este proceso cultural. 


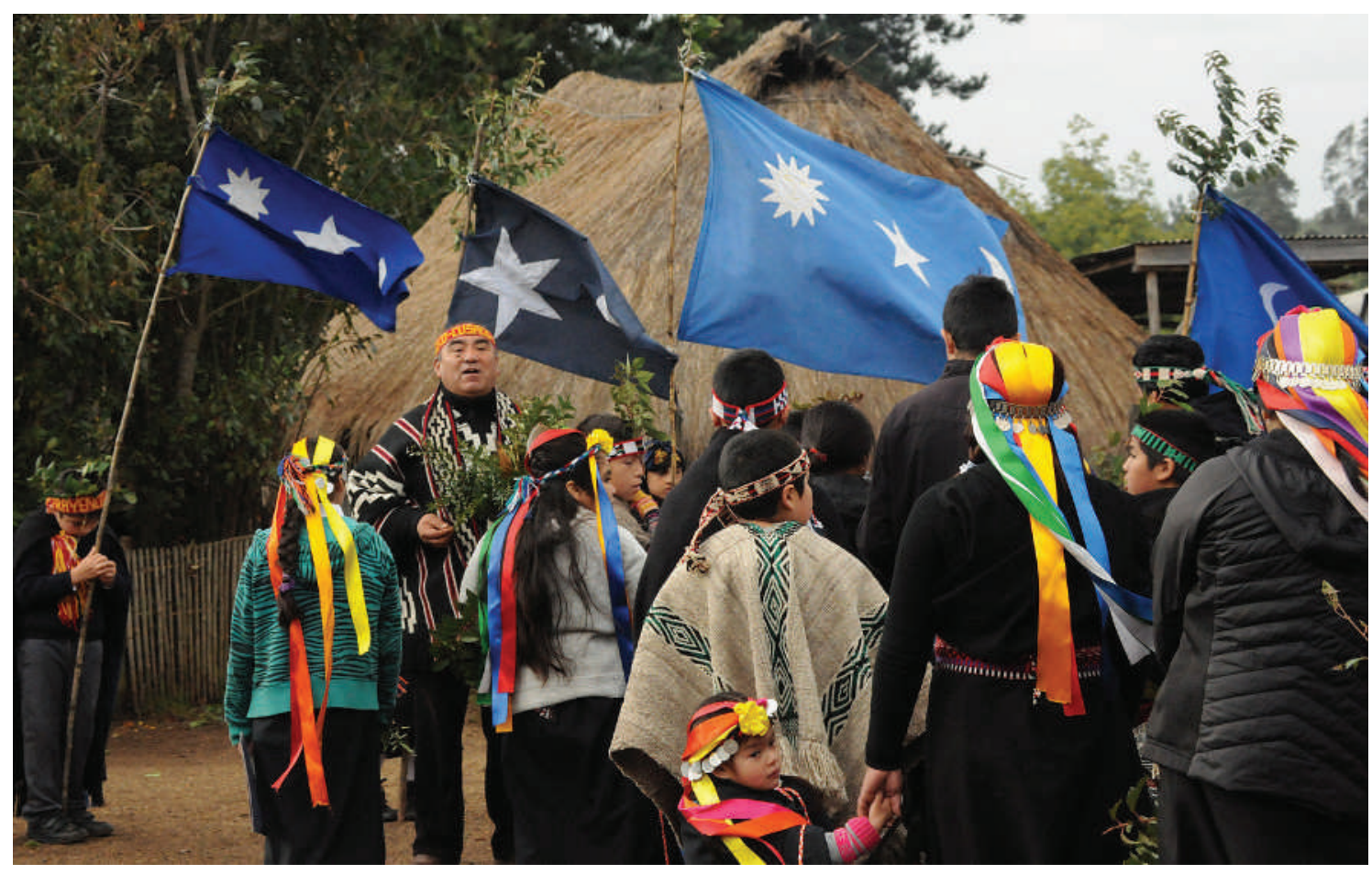

Figura 1. Celebración del Año Nuevo mapuche en una escuela rural, correspondiente al solsticio de invierno (fotografía: Rodrigo Moulian, comunidad de Cusaco, Nueva Imperial, año 2014). Figure 1. Mapuche New Year celebration on the winter solstice at a rural school (photo: Rodrigo Moulian, Cusaco community, Nueva Imperial, 2014).

Un trabajo señero en esta línea, por la amplitud de su perspectiva, es el de la caracterización de las áreas culturales andinas, desarrollado por Lumbreras (1969) y que recibe el apoyo de la unEsCo (Instituto Nacional de Cultura 1979). El autor emplea el concepto de 'áreas culturales', elaborado por Wissler (1917) y aplicado al territorio de los Andes centrales por Bennett (1948), para un estudio integral de la arqueología andina. El concepto de área designa aquí a zonas geográficas que presentan una serie de rasgos culturales compartidos en los que se expresa una historia social común. En esta perspectiva, la noción de cotradición denota a la "unidad general de la historia cultural de un área, dentro de la cual los componentes culturales se han ido relacionando sobre un periodo de tiempo" (Bennett 1948: 1). Elementos cotradicionales son los componentes culturales de distintos grupos sociales cuyos rasgos comunes se han configurado a partir de relaciones históricas compartidas.

En el libro Arqueología de América andina (Lumbreras 1981) se expone el resultado de este trabajo. En él se distinguen siete áreas culturales en el territorio articulado por la cordillera de los Andes. De ellas, nos ocupa aquí el área central andina, correspondiente al territorio peruano entre Piura y Arequipa; el área centrosur, que abarca el espacio circundante al lago Titicaca; de modo implícito, como zona de intermediación, el área meridional, que comprende desde el Noroeste Argentino (NOA) hasta la región central de Chile, y el área sur, correspondiente a la Araucanía. Lo interesante de este enfoque es que complejiza y diversifica el análisis de las interacciones de los pueblos situados en la macrorregión andina, tanto como al interior y entre sus distintas áreas culturales.

Diversas investigaciones aportan datos sobre esta complejidad y continuidad de los procesos interculturales ancestrales en los Andes. Desde el campo de la antropología cognitiva y simbólica, los estudios de Grebe (1995-1996, 1996, 2002) muestran la convergencia de los etnomodelos aymara, atacameño y mapuche. Dillehay (2007) ha identificado arqueológicamente un continuo de influencias andinas y amazónicas en los desarrollos culturales de la Araucanía desde el período medio. Bahamondes (2009) expone los procesos de 
andinización en la cerámica Vergel previos al desarrollo del Tawantinsuyo. El mapudungun registra influencias andinas atribuibles a diversos momentos históricos.

En un estudio nuestro sobre los afines quechuas en el Vocabulario de la Lengua de Chile, de Luis de Valdivia (Moulian et al 2015), identificamos correlaciones lingüísticas andinas que no se pueden explicar por la influencia inca. Se trata de voces que refieren a elementos culturalmente relevantes, que muestran homologías de forma y contenido con términos quechuas, y no disponen de sinónimos en el mapudungun. En este repertorio, destacan las voces antü y küyen, cuyos correlatos lingüísticos y simbólicos expresan contenidos ideológicos compartidos por diversas culturas de la región andina.

El método que empleamos aquí para su investigación es el estudio de casos de correlaciones en constelaciones semióticas. Las unidades de análisis son los motivos simbólicos del sol y de la luna en las culturas originarias de las áreas centro, centro-sur y sur andinas. La noción 'constelaciones semióticas' designa al conjunto de relaciones de significación que permiten la interpretación y funcionamiento de las unidades de sentido (Moulian 2015). Como muestra Peirce (1965), la semiosis se caracteriza por su funcionamiento en red. La interpretación del significado de un signo requiere de otros significados que lo traduzcan, los que a su vez demandan sus propios interpretantes. A este encadenamiento potencialmente sin fin se le denomina 'semiosis ilimitada'. No obstante, como advierte Eco (1992 [1990]), en las prácticas semióticas esta deriva se delimita a un conjunto de relaciones de significación que resultan pertinentes y relevantes para la interpretación de las unidades de sentido. A estas configuraciones operativas de la semiosis, que hacen posible la interpretación y funcionamiento de los signos y textos, es lo que denominamos 'constelaciones semióticas'. Estas, evidentemente, no constituyen entidades semióticas fijas, pues dependen de los conocimientos y perspectivas de los intérpretes, que varían de acuerdo a las competencias semióticas, grados de especialización y posición social.

En nuestro caso de estudio, indagamos las constelaciones semióticas del sol y de la luna en culturas de las áreas centro y sur andinas. Es decir, leemos las estructuras de sentido que modelan las concepciones de estos astros en estos contextos. Esta tarea supone el análisis de los paradigmas lingüísticos en los que se inscriben los términos del lenguaje, como de las enciclopedias culturales y prácticas discursivas contextual- mente situadas que ponen en uso los saberes sociales. El estudio de las configuraciones interpretativas de la semiosis requiere atender los significados directamente implicados en la definición de los términos, es decir, en el plano de la designación o denotación. Exige atender a los significados consecutivamente implicados por los conceptos empleados en la definición, a los que proponemos denominar 'significados presupuestos'. Precisa registrar las relaciones de significación connotadas, es decir, la existencia de otras relaciones de significación que se establecen sobre la base de las primeras. Demanda observar los usos sociales de los significados previamente referidos y las prácticas donde se emplean o se encuentran implicados. Supone atender a otros significados con los que se asocian en los usos y prácticas.

Las relaciones de significación implicadas, presupuestas, connotadas y asociadas configuran cognitivamente representaciones sociales, es decir, estructuras de conocimientos conceptuales y figurativas de los motivos de referencia. El despliegue de las mismas en las prácticas modela patrones de comportamientos. Representaciones cognitivas y patrones conductuales constituyen modelos culturales en los que se plasman las constelaciones semióticas. Por lo mismo, su análisis comparativo permite poner en evidencia vínculos o relaciones interculturales. Cuando en el análisis contrastante de representaciones y patrones conductuales se advierte la recurrencia transcultural sistemática de relaciones de significación, ello deja en evidencia una textura cultural compartida, que no se produce naturalmente.

Debe advertirse, para la lectura de las mismas, que las representaciones sociales y los patrones conductuales son recursos disponibles para la acción humana, que se los apropia y emplea creativamente de acuerdo a situaciones siempre cambiantes y con diversas intenciones. Las constelaciones semióticas no son entidades fijas. Los modelos culturales en los que ellas se plasman tampoco lo son. El análisis intracultural de estos nos muestra siempre sistemas de variantes en el uso de representaciones y patrones. Las evidencias de relación intercultural de los mismos deben buscarse en la recurrencia de las estructuras de información que los organizan, no en formas textuales idénticas, como mostraremos.

Para la referencia de los contextos socioculturales de pertenencia de los datos que exponemos, recurrimos a diversas categorías vinculadas entre sí. Empleamos los etnónimos para designar a los grupos sociales identitarios: inca, aymara, mapuche. El término 'cultura' lo usamos, 
asociado a los etnónimos, para denominar patrones simbólicos y pautas de comportamiento distintivos de los grupos sociales. La categoría de 'mundo' la ocupamos para denotar el universo de contenidos que modela la experiencia de conocimiento de los portadores de una cultura. Cuando la noción de 'espacio' acompaña a estos etnónimos, aludimos al territorio donde las culturas se han desarrollado. Una situación particular se da en el caso inca, donde debe distinguirse entre el territorio originario de emplazamiento, en el Cusco a partir del siglo XII, y su expansión imperial, que da lugar al Tawantinsuyo en el siglo xv. El adjetivo 'imperial' y el sustantivo 'imperio' lo empleamos para aludir a esta fase de desarrollo en la que los incas ocupan la zona central del territorio chileno, hasta el río Maule.

De modo adicional, para relacionar geoculturalmente los datos, empleamos el marco categorial de Lumbreras (1981) sobre las áreas culturales andinas. Como muestra este autor, inscribir la Araucanía en el área sur andina presupone que su historia cultural, si bien tiene particularidades, no puede ser comprendida al margen de los procesos que se desarrollan en la macrorregión de los Andes y sus respectivas áreas culturales. Es lo que, desde distintas matrices disciplinarias, han venido planteando los estudios sobre el proceso de andinización.

\section{HOMOLOGÍAS LINGÜÍSTICAS}

Un punto que resulta evidente es el de las homologías lingüísticas entre las voces mapuche y quechua para designar a los astros dominantes desde el campo visual terrestre. Inti [inti] designa al sol en quechua (González de Holguín 2007 [1608]: 209); antü [ent9] en el mapudungun central significa sol, pero esta voz se registra, igualmente, bajo la forma anti [enti] (Cañas 1910, Moesbach 1980). Según Erize (1960:54), esta variante es propia del habla puelche, variedad dialectal hablada en Argentina. Killa

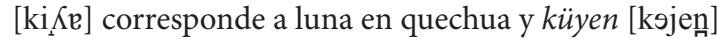
en el mapundungun central, mientras killen [kijen] es la voz que se registra en el dialecto veliche (Cañas 1910), hablado en Chiloé.

Este correlato en las formas que nombran al sol fue advertido por Havestadt (1883 [1777]), comentado por Augusta y Fraunhäusl (1910), analizado por Cañas (1910), registrado por Englert (1934). El paralelismo para el caso de la luna es consignado por Cañas (1910). Díaz-Fernández (1992) ofrece un análisis lingüístico de ambas homologías, consideradas como unidades tópicas. La idea dominante entre los investigadores es que este correlato informa el contacto del quechua-mapudungun. No obstante, Augusta y Fraunhäusl (1910) advierten que la ausencia de sinónimos para antü en el mapudungun problematiza la idea del préstamo lingüístico en el período de expansión inca, en el siglo xIv. De ser este el caso, quedaría registro de la voz ancestral para designar al astro en esta lengua, lo que no sucede.

Cabe destacar que inti, igualmente, designa al sol en aymara (Bertonio 2015 [1612]), pero esta lengua registra la voz willka, como forma arcaica de denominar al sol. Paqsi es, en tanto, el término que designa 'luna' en la misma. La voz inti, con el sentido de sol, pertenece también al repertorio léxico del puquina (Torero 2005, Cerrón-Palomino 2013a), la tercera lengua general andina hoy extinta. Se da la particularidad de que el quechua dispone de la voz punchao como sinónimo para sol, término que presenta una extensión semántica y variantes de sentido bastante próximas a la voz inti de la misma lengua. Esta duplicidad terminológica es uno de los argumentos a favor del posible origen puquina del lexema, como ha argumentado Cerrón-Palomino (2013a).

Diversos antecedentes etnohistóricos, arqueológicos y míticos respaldan esta tesis. Existe cierto consenso en torno a que el puquina ha sido la lengua de Tiwanaku (Torero 1972, 1987; Bouysse-Cassagne 1987, Espinoza 1987, Aguiló 2000, Cerrón-Palomino 2013a), porque el espacio de irradiación del registro arqueológico de esta cultura coincide con el registro etnohistórico de la localización de hablantes de esta lengua. Al momento del colapso de Tiwanaku, fechado alrededor del año 1000 DC, se habrían producido flujos migratorios que conducen a la población puquinahablante hacia el norte. $\mathrm{Al}$ respecto, uno de los mitos del origen del incario señala al Titicaca como cuna de sus fundadores (CerrónPalomino 2013b). Diversos términos correspondientes al lenguaje institucional del incario se encuentran en el registro léxico puquina de Jerónimo de Oré (1607), lo que indicaría una impronta puquina sobre la cultura del Tawantinsuyo (Cerrón-Palomino 2016).

En cuanto al término killa, cabe destacar la presencia de la raíz illa en su estructura, término que presenta un extenso campo semántico, pero en cuyo sentido comprensivo en quechua designa a la luz como forma de energía primordial. Como señala Arguedas (2006 [1958]: 114), "Illa nombra a cierta especie de luz y a los monstruos que nacieron heridos por los rayos de la 
luna”. En palabras del autor (Arguedas 2006 [1958]: 117), illa es "la propagación de la luz no solar [...], el claror, el relámpago, toda luz vibrante". En tanto, en aymara el término denota una energía "guardiana, protectora, conservadora, multiplicadora" (Mamani 2012: 254). Según Aguiló (2000), su afín en puquina es la voz ila que denota 'resplandor'.

El término illa participa, igualmente, de la constitución de voces que denominan a fenómenos atmosféricos asociados a las tormentas, como el trueno, el rayo y el relámpago. Entre estas se encuentran, respectivamente, intiillapa, chuqiilla y catuilla, considerados deidades incaicas (Cobo 1892 [1653]). También se registra en las denominaciones de entidades astronómicas, con las que las primeras se relacionan. Así, Guaman Poma (1980 [1615]: 56) identifica como Chuqi Illa willka al lucero del amanecer, representado en el escudo de armas de los incas. Esta expresión literalmente significa la "lanza brillante del sol", refiriendo al poder generador de rayos que se atribuía a esta entidad astronómica. Ramos (2013: 291) señala que Catequilla significaría "el que sigue a la luna", en alusión al planeta Venus que suele alinearse con la luna.

La partícula illa se encuentra, también, como componente de los nombres que designan a conjuntos estelares en nombres como catachillay que, según Zuidema (1982a), nomina a las Pléyades, tanto como a Alfa y Beta de Centauri, y orqochillay que nombra a Lira, la constelación de la Cruz del Sur. Al respecto señala Garcilaso de la Vega (2012 [1609]: 229): “[a] las estrellas tenían por criadas de la luna [...], porque decían que las estrellas andaban en el cielo con la luna como criadas suyas y no con el sol -porque las ven de noche y no de día". Como vemos, en forma y contenido el término illa constela en torno a la luna, killa.

En tanto, en mapudungun, la voz küyen y la variante killen designan 'luna' y 'mes', las mismas acepciones que killa tiene en quechua (Rosat 2009 [1998]: 531-532, Urton 2006: 85). La lengua mapuche no dispone de otra voz con la misma extensión semántica. El término ale se emplea para designar a la luz de la luna y las estrellas, en ocasiones se emplea como sinónimo de luna, pero su denotación no es equivalente. La ausencia de sinónimo es un argumento contrario a la hipótesis de la incorporación del término por la influencia del quechua imperial. Debe tenerse en cuenta que la expansión del Tawantinsuyo a la zona central del actual territorio chileno se ha estimado según la datación de restos cerámicos alrededor del año
1390 DC (Cornejo 2014). No obstante, su presencia en el territorio mapuche se ve restringida tanto en términos temporales como espaciales a través de un patrón de ocupación en forma de archipiélagos localizados y dispersos (Dillehay \& Gordon 1998).

Los datos previamente reseñados no son consistentes con la hipótesis de los efectos aculturadores generales de la expansión del incario sobre los mapuches. Si los términos antü y küyen fuesen quechuismos, debiera mantenerse en el mapudungun el registro de la voz originaria que designa al astro, lo que no sucede.

\section{INDICADORES DEL TIEMPO-ESPACIO}

La observación y estudio de los movimientos del sol y de la luna ha ocupado un lugar destacado en las sociedades precolombinas andinas (Ziólkowski \& Sadowski 1992, Malville 2014). En ellas, la contabilidad de las fases de la luna y el seguimiento de las posiciones relativas del sol sirven de base para la elaboración de los calendarios y la organización de las actividades agrícolas. El caso mejor documentado es el de los incas, quienes desarrollaron una importante tecnología para el estudio de los astros (Dearborn \& Schreiber 1989, Bauer \& Dearborn 1998). Como parte de ella se cuenta el uso de postes que permiten seguir la proyección de la luz, la construcción de torres como puntos de referencia para seguir el movimiento del sol, el diseño de edificaciones cuyas ventanas permiten fijar la posición de este astro o de la luna a través de la proyección de la luz en distintos momentos. El uso de estos dispositivos de observación se extiende a través del Camino del Inca, como lo muestra Sanhueza (2005, 2017) en sus investigaciones sobre las saywas o postes de medición dispuestos en las rutas que cruzan el desierto de Atacama.

Cabe señalar que los incas son continuadores y herederos de una larga tradición andina de estudios astronómicos. El observatorio más antiguo en el área es el de Chankillo, situado en Casma, con una estimación de 400 al 0 AC (Ghezzi \& Ruggles 2006). Este se compone de una serie de torres que actúan como hitos de referencia a través de los cuales se pueden analizar los patrones de movimientos del sol y de los astros.

La continuidad en el uso de patrones arquitectónicos con alineación astronómica ha quedado registrada en el templo de Pachakamaq, ubicado en el valle de Rimac, en el centro de Perú. Allí se han registrado orientaciones 
solares, lunares y estelares de numerosos edificios desde el Período Intermedio (Pinasco 2007). La ocupación incaica de este espacio muestra la persistencia en el desarrollo de estos patrones de construcción.

Otro antecedente directo de la etnociencia inca es el desarrollo de saberes astronómicos que muestra Tiwanaku. El templo de Kalasasaya, también conocido como Templo de las Piedras Paradas, presenta una perfecta alineación en relación con equinoccios y solsticios, que marcan los cambios estacionales en el ciclo solar. En los equinoccios, la luz ingresa a través de la puerta central del recinto (Ibarra 1982, Riveros 1996). En los solsticios, lo hace desde el vértice del emplazamiento (noreste en invierno y sureste en verano). La arquitectura ritual inca muestra recurrentemente este tipo de alineaciones astronómicas, asociadas a la observación de los ciclos naturales (Pino 2004, Moyano 2014).

Si bien existen abundantes antecedentes sobre el desarrollo de la astronomía incaica, no se ha alcanzado un consenso sobre su sistema de contabilidad del tiempo. Zuidema (1982b, 2010) ha postulado que los incas manejaban un calendario sideral lunar, cuyos meses se calculan por el tiempo en que tarda la luna en volver a pasar junto a un punto estelar fijo. El año se compondría de doce meses sidéreos, de 27 1/3 días, que suman 328 días, más un mes extranumerario de 37 días. En contraste, Ziólkowski $(1989,2015)$ y Bauer y Dearborn (1998) postulan un calendario luni-solar, con meses sinódicos, que contabilizan la sucesión de los ciclos de la luna, que se ajustan al año solar. Ortiz (2012) argumenta en favor de un calendario solar, institucionalizado con la expansión del imperio, pero admite la posible subsistencia de un calendario lunar, como reminiscencia de épocas anteriores. En contraste, D’Ans y Aguirre (2016) señalan que la extensión territorial del Tawantinsuyo, que comprende diferentes ecosistemas, requiere diversos modos de organización del tiempo y hace disfuncional un calendario único.

Lo que resulta indiscutible es que los incas dispusieron de un denso sistema de categorías lingüísticas para distinguir las fases de la luna, registradas por González de Holguín (2007 [1608]), cuyo inventario nos provee Ziólkowski (2015). También, que emplearon los ciclos sinodales para seguir la consecución del tiempo, puesto que el término quilla $[\mathrm{ki}, \underline{\mathrm{k}}]$ que refiere al astro designa, igualmente, 'mes'. Al mismo tiempo, se encuentra documentado que dispusieron de un sistema de observación de los movimientos del sol que les permitió fijar sus ciclos estacionales mediante la identificación de solsticios y equinoccios, marcados ritualmente a través de fiestas dedicadas al sol (Guaman Poma de Ayala 1980 [1615]). En tanto tal, parece apropiado caracterizar su calendario como 'luni-solar'.

Lo relevante, para nosotros, es que estos sistemas de distinciones se repiten en el territorio andino, registrándose en los marcos de conocimiento aymara y mapuche. La doble acepción que registra el término quechua killa, con el significado de 'luna' tanto como 'mes', se registra también en la voz aymara phaxsi (Bertonio 2015 [1612]) y en el lexema küyen (Augusta 1916: 108) del mapudungun. Por otra parte, en los sistemas calendáricos de estas culturas, el solsticio de invierno se considera el inicio del ciclo anual. De allí que algunos autores señalen el carácter panandino del calendario (Grebe 1990, Valeriano 2002). Una manifestación conspicua de esta correlación cultural es la sincronización de los rituales de celebración del Año Nuevo entre el 21 y el 24 de junio: Inti Raymi en el caso quechua, Machaq Mara en el aymara y Wetripanantü en el mapuche (fig. 1). Para los atacameños, en tanto, el nacimiento del sol se asocia a la fiesta de San Juan, el 24 de junio (Cruz et al. 2013), en cuyas vísperas siguen el movimiento del astro en el horizonte y observan lo que ocurre en el cielo (Castro \& Varela 2004). Si bien las formas rituales actuales de estas culturas han experimentado una importante reinvención en el curso de los procesos de revitalización étnica o patrimonialización identitaria, sus prácticas tienen antecedentes ancestrales. Las fuentes etnohistóricas documentan la celebración del IntiRaymi en el incario; las etnolingüísticas registran desde antaño los términos que nombran estos eventos:Willkakuti (Bertonio 2015 [1612]: 515) y Tripantu (Valdivia 1887 [1606] s/n) o Wetripantü (Augusta 1916:254). En estas sociedades, el sol constituye un ordenador del tiempo y del espacio, que organiza el calendario y fija simbólicamente al naciente como principal punto de referencia geográfico.

La importancia simbólica del sol como indicador ha quedado registrada en los textiles Q'ero, grupo étnico quechua hablante del área cusqueña de Paucartambo, considerado como 'el último ayllu inka' (Núñez del Prado et al. 2005 [1955]). Los diseños de sus tejidos representan iconográficamente al astro en los momentos del naciente, poniente, cénit, anticénit (Silverman-Proust 1986), durante los solsticios y en su relación con la organización del espacio (Silverman-Proust 1988). El registro iconográfico del sol en estos hitos espacio-temporales perfila el 
posicionamiento del astro como un punto de referencia estructurante. Urton (2006) ha documentado etnográficamente la vigencia en comunidades quechuas de los sistemas de observación astronómicos sobre puntos de referencia geográficos. Al respecto, el autor informa que, en este contexto, el levante, denominado intisiqamuna (lugar donde nace el sol), es el principal punto direccional marcado lingüísticamente. Por su parte, Matos (1994: 48) sostiene que entre los pastores de Junín "la geografía física es entendida en perspectiva solar", puesto que el espacio se organiza sobre la distinción primaria Este-Oeste, cuyos puntos de referencia reciben los nombres de Inticcespimunan (Este) y el Intiseccaycunan (Oeste). Cáceres (2016) añade que en el contexto andino los patrones de movimiento ritual asumen predominantemente un sentido contrario a las agujas del reloj, con desplazamientos trazados circularmente de derecha a izquierda. Este patrón reproduce el sentido del eje de rotación de la tierra que define la trayectoria aparente del sol en el curso diurno.

Una manifestación de la correlación en las constelaciones semióticas centro y sur andinas es la recurrencia de estos principios proxémicos que organizan el diseño del espacio y los movimientos dentro de este. El patrón de orientación solar se encuentra nítidamente marcado en las culturas aymara y mapuche de un modo más distintivo que en las comunidades quechuas. Van den Berg (1989: 192) señala que al oriente se le atribuye un sentido positivo en la cultura aymara por diversos motivos:

\footnotetext{
Por allí aparece cada día el sol que tempera al hombre y a la tierra después del frío de la noche. Desde allá vienen las lluvias que fecundan la tierra. Los valles del oriente, con su exuberante vegetación son símbolos de fertilidad y de abundancia, y las tierras fértiles del altiplano son como un reflejo, aunque pobre, de la abundancia del oriente. Es por todo eso que los ejecutores de los ritos siempre se colocan en dirección al oriente.
}

En contraste, al oeste se le asigna un sentido negativo porque por allí desaparece el sol "causando que hombres, animales y tierras se hundan en el frío de la noche" (Van den Berg 1989: 192).

Van Kessel (1980a, 1982) denomina 'el arco de la vida' al eje de articulación levante-poniente que estructura simbólicamente la concepción del espacio en la cultura aymara de Tarapacá. Esta metáfora alude al movimiento del sol y del agua como elementos vitales. En palabras del autor (1980b: 138):

\begin{abstract}
[...] los santuarios locales y aún las casas habitacionales, están orientadas con la puerta hacia el oriente para recibir, en la mañana, los primeros rayos del sol. La oración se dirige también hacia el oriente, y en esa dirección se quema el incienso, en la madrugada, para 'adorar al Señor'. El primer nivel ecológico -el altiplano- equivale, para el aymara, al origen de toda vida y fuerza. El arco de la vida se levanta -como el sol- en el oriente, alcanza su cumbre en el 'centro': la cordillera, y desciende en el occidente (Van Kessel1980b: 132).
\end{abstract}

La prevalencia de este patrón de organización espacial en el mundo aymara se encuentra documentada en los dominios del ritual (Motta 2011) arquitectónico y urbanístico (Magaña 2006), y constituye, según Núñez y Cornejo (2012), un marco de referencia absoluto que define al 'naciente del sol' como lo que se tiene enfrente. Al respecto sintetiza Tschopik (2015 [1951]: 319):

Está demostrado por numerosos contextos que el Este es la dirección ceremonial más importante de la cultura aimara. Las casas se construyen generalmente con sus puertas mirando al Este... En los sacrificios de sangre se coloca al animal frente al Este, de modo que la sangre mane hacia el sol naciente. Durante los ritos, los magos se sientan siempre mirando al Este y generalmente las libaciones e incienso se ofrecen en esa dirección. Incluso los altares cristianos, construidos en sitios donde antiguamente hubo una apacheta aimara, están casi siempre orientados hacia el Este.

En cuanto a la representación del tiempo, Grebe (1990: 79) señala: "Tanto el ciclo día-noche como el ciclo anual aymara se caracterizan por compartir un movimiento circular básico, contrario a la dirección de los punteros del reloj”. Este trazado propio del eje de rotación de la tierra, que va de derecha a izquierda, constituye el patrón de desplazamiento dominante en el mundo aymara. El mismo se expresa en el movimiento de los yatiris en torno a las mesas rituales, en la circulación de los grupos de danzantes en torno a las plazas, en las rondas de carnaval, en el orden protocolar para la distribución de saludos y alimentos. Estos patrones que organizan el espacio y movimiento en la cultura aymara se repiten en el mundo mapuche.

En la concepción horizontal del espacio que organiza al Nag Mapu, el mundo donde vive la gente mapuche, el este es el punto de orientación fundamental, en tanto se encuentra asociado a la claridad, a la luz que provee el sol (Grebe et al. 1972, Briones \& Olivera 1985). Al levante se le atribuye un carácter positivo, se le asocia a la vida y a la fertilidad, se lo considera limpio y poderoso. Por 
lo mismo, los actos de propiciación se dirigen al oriente; las canchas de rogativas se disponen hacia esta dirección, las puertas de las viviendas apuntan generalmente al naciente del sol, la gente duerme mirando hacia la salida del astro. En contraste, el oeste es considerado negativo, se asocia a la oscuridad y a la muerte. Para el mapuche, las horas adecuadas para iniciar una actividad son las primeras de la mañana, con el ciclo de ascenso de la luz. Nuestra experiencia etnográfica en las áreas de Boroa y Panguipulli, ratificada por testimonios para el área del Budi, señalan esta pauta general. Las acciones relevantes no se emprenden pasado el mediodía, porque este momento marca un cambio en el ciclo de la luz que no resulta propicio.

Los movimientos de circulación en el espacio se realizan desde la derecha hacia la izquierda, en el sentido contrario a los punteros de nuestro reloj, reproduciendo el wallontumapu. Con este término se denomina al giro cósmico, por el cual se define el movimiento aparente del astro en el curso diario. Este patrón se expresa en el awün, como se designa al movimiento de los jinetes en torno a los espacios rituales para protegerlos de la acción de los malos espíritus, en el baile ceremonial comunitario en torno a los campos rituales, en la distribución de los saludos cuando se ingresa a algún lugar, en la entrega de alimentos y bebidas, cuando se distribuyen los platos, se sirven los vasos de chicha o se hace circular entre los comensales el mate que sigue a las comidas o acompaña en los encuentros interpersonales.

\section{REPRESENTACIONES SOCIALES}

Los movimientos astronómicos de la tierra definen el ciclo de la luz, los ritmos circadianos asociados a ellos, el curso de las estaciones climáticas y los procesos agropecuarios y sociales que se les vinculan. Por lo mismo, resulta explicable, en términos indexales, el desarrollo de patrones de organización del tiempo-espacio convergentes $\mathrm{o}$, incluso, coincidentes, orientados al uso de la luz. Lo que no resulta explicable, del mismo modo, es el desarrollo de narrativas sociales concordantes de los cuerpos celestes, como las que se registran en las áreas centro y sur andinas. Aquí se ha labrado culturalmente una concepción del sol y de la luna como una pareja matrimonial divina, con adscripciones de género que identifican al sol como varón y a la luna como mujer. Las estrellas, en tanto, son consideradas su prole. Se articulan en esta narrativa cultural tres dominios: teológico, de filiación y de género, que se intersectan con las concepciones del tiempo y el espacio, exponiendo un sorprendente correlato en las constelaciones semióticas del sol y de la luna. En ello se deja ver un tipo particular de textura cultural compartida. En contraste, en la región amazónica predomina una representación de estos mismos astros como hermanos gemelos varones, que compiten entre sí, es decir, un modo distinto de concebir y constelar las concepciones (Blixen 2013).

La religión inca constituye un paradigma de este modelo de representaciones compartidas en el mundo andino. Al respecto, Murúa (1922 [1590]: 24) señala que los cusqueños "idolatraban regiamente, adorando al sol y la luna, teniéndolos por marido y mujer y por muy grandes dioses, $y$ a las estrellas por muy verdaderas hijas suyas". A ambas figuras se les rendía culto en el templo de Qoricancha, el principal templo de la capital del imperio. El cronista mestizo Juan Santa Cruz Pachacuti Yamque (1879 [1613]) provee una reproducción de la lámina de oro que cubría el altar mayor, considerado un cosmograma porque alude a las principales divinidades del imperio (fig. 4). En la parte superior del diseño se ubican las figuras del sol y de la luna, situadas respectivamente a la derecha e izquierda del altar. El Qoricancha albergaba igualmente adoratorios dedicados específicamente a los astros mayores, representados en formas de figuras humanas de oro macizo, el sol, y plata, la luna. Los miembros de la monarquía se consideraban descendientes de estos (Garcilaso 2012 [1609]), de modo que el inca se tenía como hijo del sol y a la coya, de la luna.

Se estima que durante el gobierno de Pachakuteq, noveno emperador inca, el culto al sol devino en la religión oficial del imperio (fig. 2a). En Cusco se celebraban anualmente sendas fiestas en honor al sol durante los solsticios (fig. 2b), y a la luna en el mes de septiembre. En las islas del lago Titicaca donde, de acuerdo a la narrativa mítica, los astros habrían nacido, se levantaron templos, que se transformaron en centros de peregrinaje para los pueblos del imperio. Con la caída del mismo, el sistema cúltico institucionalizado sufrió un importante proceso de desestructuración. No obstante, durante la Colonia subsiste el culto al sol en espacios regionales (Cook \& Doyle 1978). Hasta el presente, los términos tayta inti (padre sol) y mama killa (madre luna) se mantienen en uso en las comunidades quechuas para referir a los astros (Steele \& Allen 2004). Mishkin (1940) registra 


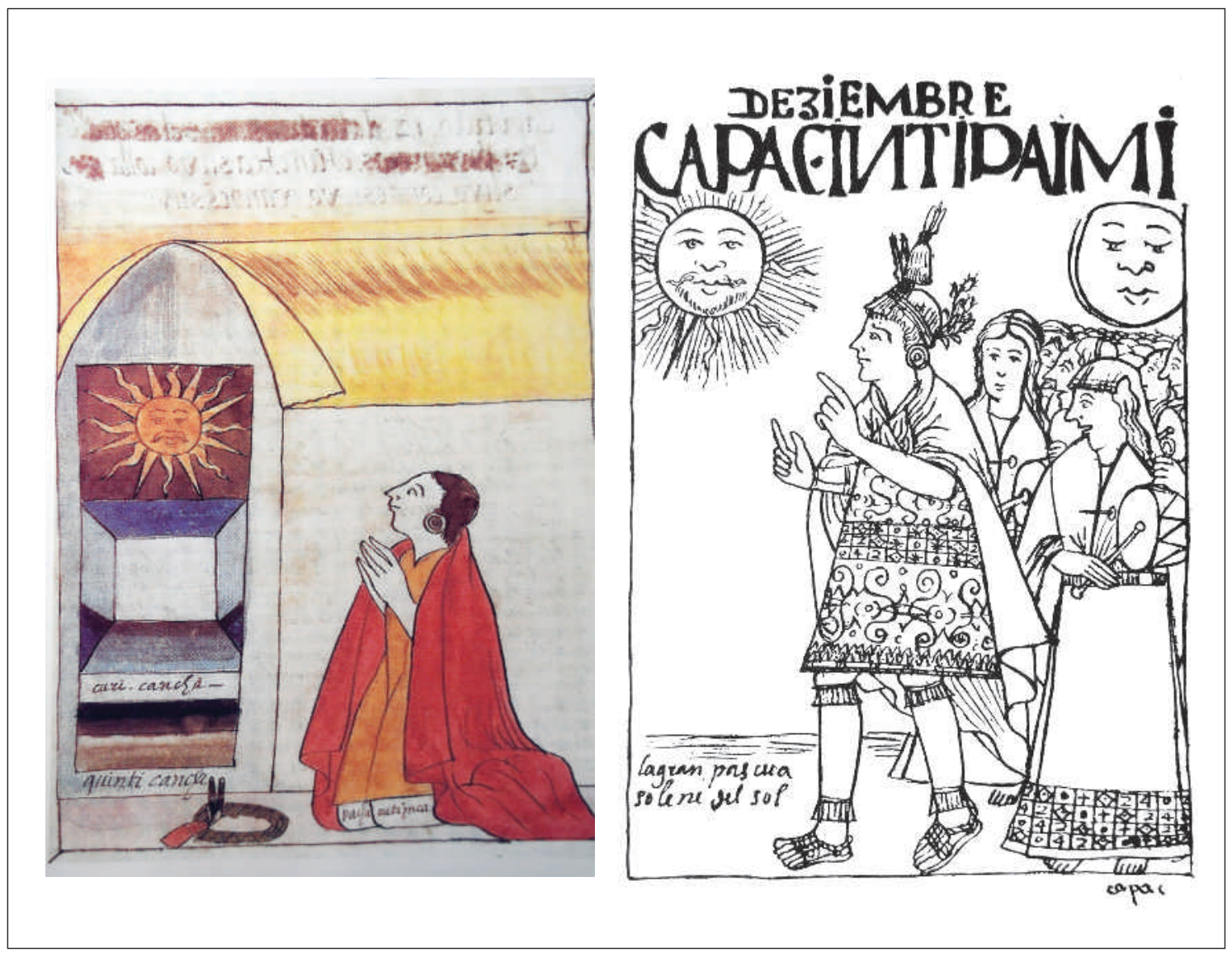

Figura 2: a) el Inca adorando al sol según Martín de Murúa (2004 [1590]); b) celebración del Kapaq Raymi, fiesta del sol, coincidente con el solsticio de verano, ilustrado por Guaman Poma de Ayala (1980 [1615]). Figure 2: a) Inka worshiping the sun, by Martín de Murúa (2004 [1590]); b) celebration of Kapaq Raymi, festival of the sun, coinciding with the summer solstice, illustrated by Guaman Poma de Ayala (1980 [1615]).

etnográficamente en la comunidad de Kauri (Quipicanchis, Cusco) persistencias del mismo. Allí, todas las mañanas, al rayar el sol, los comuneros elevan sus manos para realizar oraciones propiciatorias en su dirección, puesto que consideran que este es dador de vida, pues provee luz, calor y energía que fertiliza sus sementeras.

Una sobrevivencia de su culto la hemos observado en la fiesta del Señor del Qoyllur R'iti, la mayor peregrinación religiosa del área de Cusco, en un momento ritual denominado 'Inti Alabado' (fig. 3). Al amanecer del último día de la festividad, los peregrinos esperan con oraciones y actitud solemne el primer rayo de sol que toca sus cuerpos y exaltan su llegada con danzas y desfiles de banderas. Se expresa aquí la continuidad del culto al sol y a los nevados, pero bajo una matriz cristiana, donde las figuras de Cristo y el sol se superponen (Fuenzalida 1979).
De igual forma sucede en el espacio aymara boliviano (García 2013), donde el culto al sol con sus rituales de alba se desarrolla en el marco del Corpus Christi. Tschopik (2015) y Abercrombie (1998) informan de la asociación simbólica del sol y Cristo entre los aymaras de Chuquito y K'ulta, quienes consideran al Hijo de Dios de la teología cristiana una encarnación del astro. La asociación entre la luna y la Virgen, en tanto, tiene una expresión paradigmática en la iconografía de Nuestra Señora de Copacabana, cuya imagen se levanta sobre una luna naciente. Si bien los astros no tienen en el presente un lugar central en la religión aymara, ellos se inscriben dentro del culto a los elementos de la naturaleza (Van den Berg 1989). En el habla actual de los comuneros, sol y luna mantienen los nombres de Tayta Inti y Mama Pacsi, los que son invocados en diversos actos rituales. Así sucede, por ejemplo, en las 


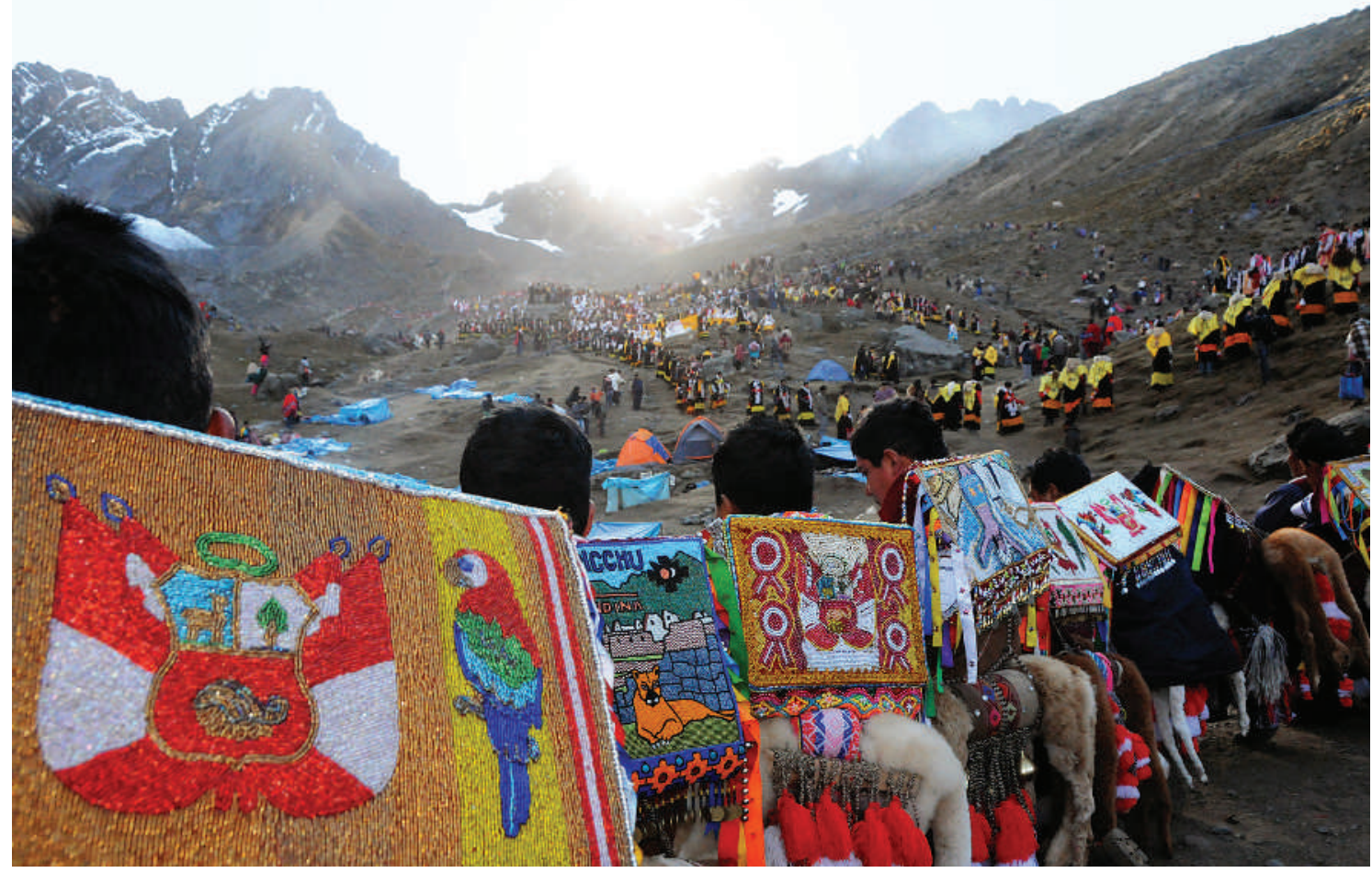

Figura 3. Inti Alabado, culto al sol en el marco de la fiesta del Señor del Q’oyllur riti (fotografía: Rodrigo Moulian, nevado Sinakara, Perú, año 2014). Figure 3. Praising Inti, sun worship at the festival of the Lord of Q'oyllur riti (photo: Rodrigo Moulian, Sinakara Peak, Peru, 2014).

prácticas simbólicas asociadas a la construcción de las casas, donde se reproducen en pequeña escala los componentes del cosmos. En palabras de Arnold et al. (1998: 105-106), "En la actual división de labor ritual por sexo concerniente a la challas durante la construcción de una casa, los hombres recuerdan a su 'Senda del Padre' y las mujeres recuerdan a su 'Senda de la Madre'. Los Qaqas dicen que estos términos se refieren a sus dioses, puesto que las mujeres hallan, en último término, su origen en la mama luna (Mama Santísima) y los hombres en el tata sol (Tata Santísimo)".

De acuerdo con el registro histórico del cronista Juan de Santa Cruz Pachacuti (1879 [1613]), los antiguos collas rendían, igualmente, tributo al sol. Autores como Bandelier (1910) y Van den Berg (1989) plantean que ello es resultado de un ejercicio de transculturación religiosa incaica. No obstante, las orientaciones solares en la arquitectura Tiwanaku y los motivos radiantes y felínicos de su iconografía sugieren la existencia de componentes solares en el sistema religioso de esta cultura. La probable filiación puquina de la voz inti (Cerrón-Palomino 2013a) es consistente con esta hipótesis. Propio o apropiado, este patrón se vuelve persistente, pues, como declara en 1813 el cura de Andahua (Provincia de Condesuyos), "les ha quedado memoria de la adoración del sol" (Almonte 1975 [1813]: 60). El testimonio de los informantes de Tschopik (2015 [1951]: 180) deja ver la continuidad del modelo: "El sol es el padre del mundo. La luna, que es más débil, es su esposa y las estrellas son sus hijos. Cuando hay un eclipse de sol todos dicen que se acerca el fin del mundo y el juicio final".

\section{ARTICULACIONES SIMBÓLICAS}

El altar del Qoricancha dibujado por Juan de Santa Cruz Pachacuti nos presenta un cosmograma (fig. 4). Su diseño expone los elementos que configuran el mundo sagrado de los incas, ubicados simbólicamente según su importancia y relaciones. Como argumenta Barnes (1986), muchos de sus componentes se encuentran en la actualidad vigentes en las comunidades quechuas de los 


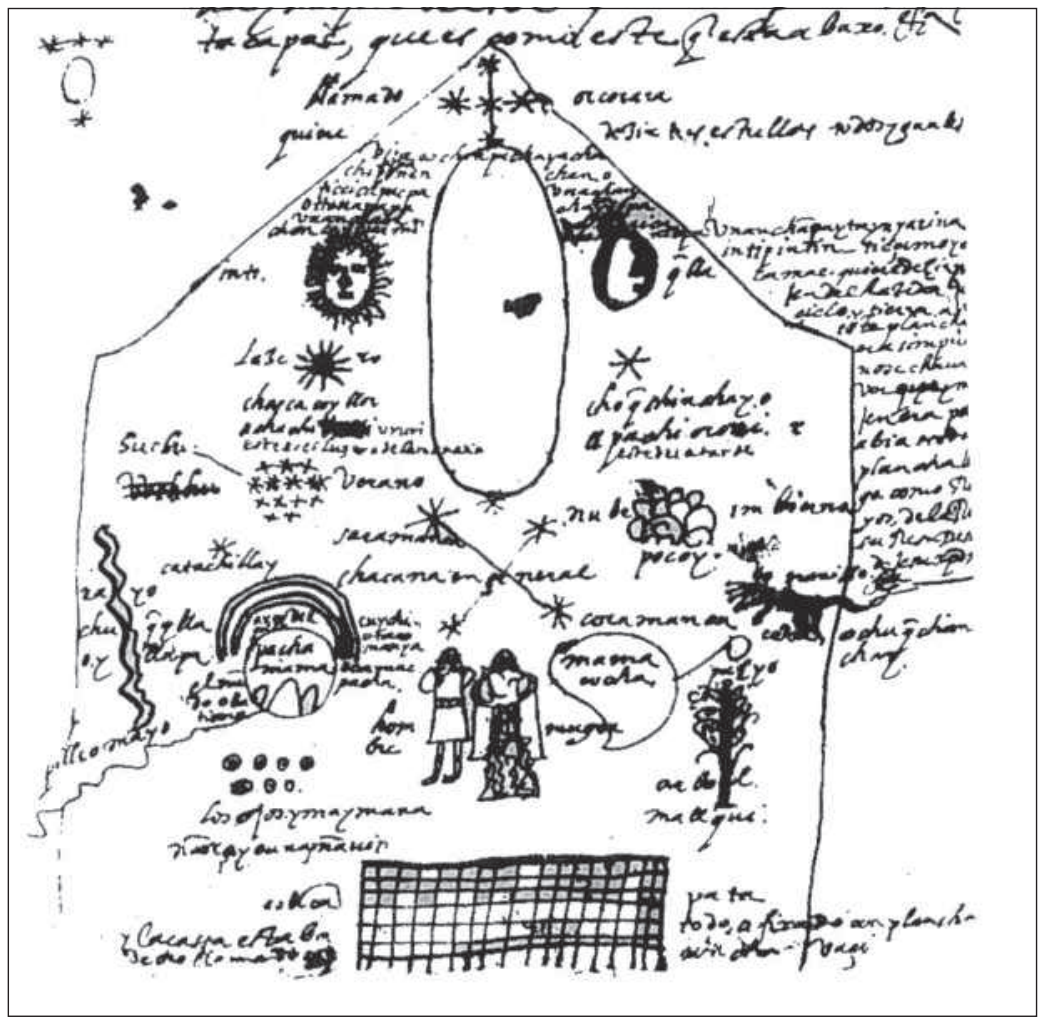

Figura 4. Representación del altar del templo del Qori Kancha de Cusco, según Juan de Santa Cruz Pachacuti (1879 [1613]). Figure 4. Sketch of the altar at the temple of Qori Kancha in Cusco, by Juan de Santa Cruz Pachacuti (1879 [1613]).
Andes centrales. La disposición de los mismos implica las categorías clasificatorias del mundo en términos de posiciones (derecha e izquierda; arriba, en medio, abajo) y expresa las relaciones que se dan entre los elementos (complementariedad, oposición y asociatividad). En cuanto tal, el diseño se puede considerar una matriz de expresión del pensamiento andino (Estermann 1998). En él, el sol, al que se considera masculino, se ubica en el espacio superior derecho. La luna, con atributo de género femenino, se sitúa en el lado izquierdo. La disposición de los elementos marca relaciones asociativas. Bajo el sol se sitúa el lucero del amanecer, el rayo y el arcoíris, y la Pachamama o Madre Tierra. Bajo la luna se encuentran el lucero del atardecer, la nube, la Mamacocha o Madre Agua, el árbol de los ancestros. Al lado derecho va el hombre, al lado izquierdo la mujer.

Como advierte Silverblatt (1987), el principio de adscripción de género tiene un carácter estructurante en el mundo andino. En este caso, al emplearlo en el plano cosmológico, como criterio clasificatorio de los astros que constituyen puntos de referencia para la organización del tiempo y el espacio, se articula en torno a ellos una compleja constelación semiótica. A los cuerpos celestes se les pliega una serie de relaciones de significación implicadas, presupuestas y connotadas por las posiciones de género. Estermann (1998) analiza este juego de asociaciones que nos muestran al sol y la luna como opuestos complementarios pero contrastantes. El sol, que es masculino, se sitúa a la derecha, que es predominantemente el lado de la mano hábil, y se le identifica con el Este, al que se le asigna un sentido positivo porque es fuente de luz. Por lo mismo, se le asocia al arcoíris, también al día y al verano, a la tierra que el astro se encarga de fertilizar y al rayo que es manifestación de energía. A la izquierda, la luna, considerada femenina, se asocia al Oeste, punto de referencia que se considera negativo, y se la relaciona con la oscuridad, la noche, el invierno, el agua y el mundo espiritual. Este juego de relaciones en la concepción de los astros coincide con los atributos que identifica Celestino (1997) en su análisis de los ciclos míticos y rituales del sol y de la luna. De acuerdo con el autor, en el calendario andino se puede identificar un tiempo solar masculino de cosecha, alumbramiento, sequía y armonía. A este se contrapone un tiempo lunar femenino, de lluvias, enfermedades, gestación, batallas rituales y muerte. 
Aunque con variantes, la vigencia etnográfica de diversos aspectos de este complejo simbólico, articulado en torno a las distinciones del sol como varón y a la luna como mujer, se encuentra registrada por Platt (1976) en la comunidad quechua de Macha, en Potosí, Bolivia. En tanto, el estudio sobre representaciones de género de Carrasco y Gavilán (2009) muestra la presencia y vigencia del mismo entre los aymaras. En el esquema que exponen las autoras, el sol también es masculino, se asocia a la derecha, al día, la puna (tierras altas) y el presente. Luna es femenina, se la vincula con la izquierda, la noche, los valles (tierras bajas), el pasado. Según Van Kessel y Cutipa, tras esta polarización se expresa una concepción relacional del cosmos: "en el pensamiento andino, el cielo y la tierra, el sol y la luna, varón y mujer, claro y oscuro, día y noche -aunque oposiciones- vienen inseparablemente juntos" (Van Kessel \& Cutipa 1998: 62). Así sucede con los astros, en nuestro caso de estudio, donde no solo los referentes sino sus atributos, asociaciones y juego de oposiciones complementarias vienen mutuamente implicadas. Como mostraremos, estas constelaciones semióticas se despliegan de modo paralelo en la cultura mapuche.

\section{CORRELATO MAPUCHE}

En el sistema religioso mapuche predomina actualmente el culto a Ngenechen, 'el controlador de los hombres' que, aunque tiene diversas representaciones, tiende a concebirse como deidad principal, creadora del universo. Diversos investigadores explican esto como producto de la acción aculturadora de la evangelización cristiana (Latcham 1924, Faron 1997 [1964], Waag 1975, Briones \& Olivera 1985, Bacigalupo 1988). Bacigalupo constata que la voz Ngenechen solo se registra en los documentos a partir del siglo xIX, problema que ya habían advertido Augusta y Fraunhäusl (1910). Faron (1997 [1964]: 50) sostiene que "la supremacía de Ngenechen, en el sentido cristiano de la divinidad, es incompatible con gran parte de las creencias mapuche". Tanto Latcham (1924) como Waag (1975) afirman que el término que lo designa es introducido por los misioneros en su esfuerzo de hacer asimilable la religión cristiana.

En contraste, el registro etnográfico de Faron (1997 [1964]), Grebe et al. (1972) y Dillehay (1990) describe un sistema religioso politeísta, naturalista y animista, compuesto por deidades y espíritus de diversa jerarquía.
En este sistema, el sol y la luna tienen una posición preeminente. La investigación de Gundermann (1981) sobre la ritualidad pewenche (mapuches de la cordillera del Pewen) identifica como deidades mayores a una pareja denominada Antü rey fucha (anciano rey sol) y Antü rey kuse (anciana reina sol), identificables uno y otra con las figuras del sol y de la luna. Del mismo modo, las oraciones williches de San Juan de la Costa identifican a Chaw Antü (padre sol) y Ñuke Ale (madre luz de luna) como figuras sagradas principales. En la Araucanía central, se mantiene vigente la creencia en una familia divina compuesta por Wenumapu Fucha (el anciano del cielo), Wenumapu Kuse (anciana del cielo), Wenumapu Weche (joven del cielo), Wenumapu Ülcha (doncella del cielo) (Marileo 1995). Estos elementos se identifican con el sol y la luna, el lucero del amanecer y el lucero de atardecer, y suelen consignarse en el kultrung o tambor chamánico o en las banderas rituales en diversas asociaciones figurativas o abstractas.

Diversos relatos míticos de la creación y de los primeros tiempos de la historia mapuche tienen como protagonistas al sol y la luna, como pareja divina. Así sucede en los textos "El Dios del cielo y sus rebeldes hijos", "Sobre Adán y Eva", "Por qué Antü, el padre sol tiene grandes penas en el corazón", "Kuyen, la madre luna se venga de una maldición", compilados por Koessler-Ilg (1996 [1954]); también en "El indio Pie de Oro narra el matrimonio del sol y de la luna", "De cuando el sol y la luna iban a quedarse dormidos", reunidos en Koessler-Ilg (2006) o en el "Texto de Chimpay", registrado por Lehmann-Nitsche (1919). En los dos primeros relatos, el sol y la luna aparecen como deidades creadoras situadas en un tiempo anterior al enfrentamiento entre las serpientes Treng Tren y Kay Kay, que se presentan como sus criaturas. No obstante, la identidad de estos dioses astros en ocasiones coincide con la de un dios único. Así lo documenta Koessler-Ilg (1996 [1954]: 18): "A nuestro Dios, que está allá arriba en el cielo azul, solían llamarlo también Antü y madre también la llamaba Luna, porque ambos se alternaban en el trabajo de darle luz a la tierra y cuidar de la gente dispersa. Algunos viejos no decían Rey Chau, sino sol y luna". De modo similar sucede hoy en día con algunas concepciones de Ngenechen, al que se figura como la integración de la familia divina (fucha, kuse, wentru, ülcha) con sus asociaciones a los astros (Marileo 1995). Un estudio de esta variabilidad puede verse en Bacigalupo (1995-1996). 


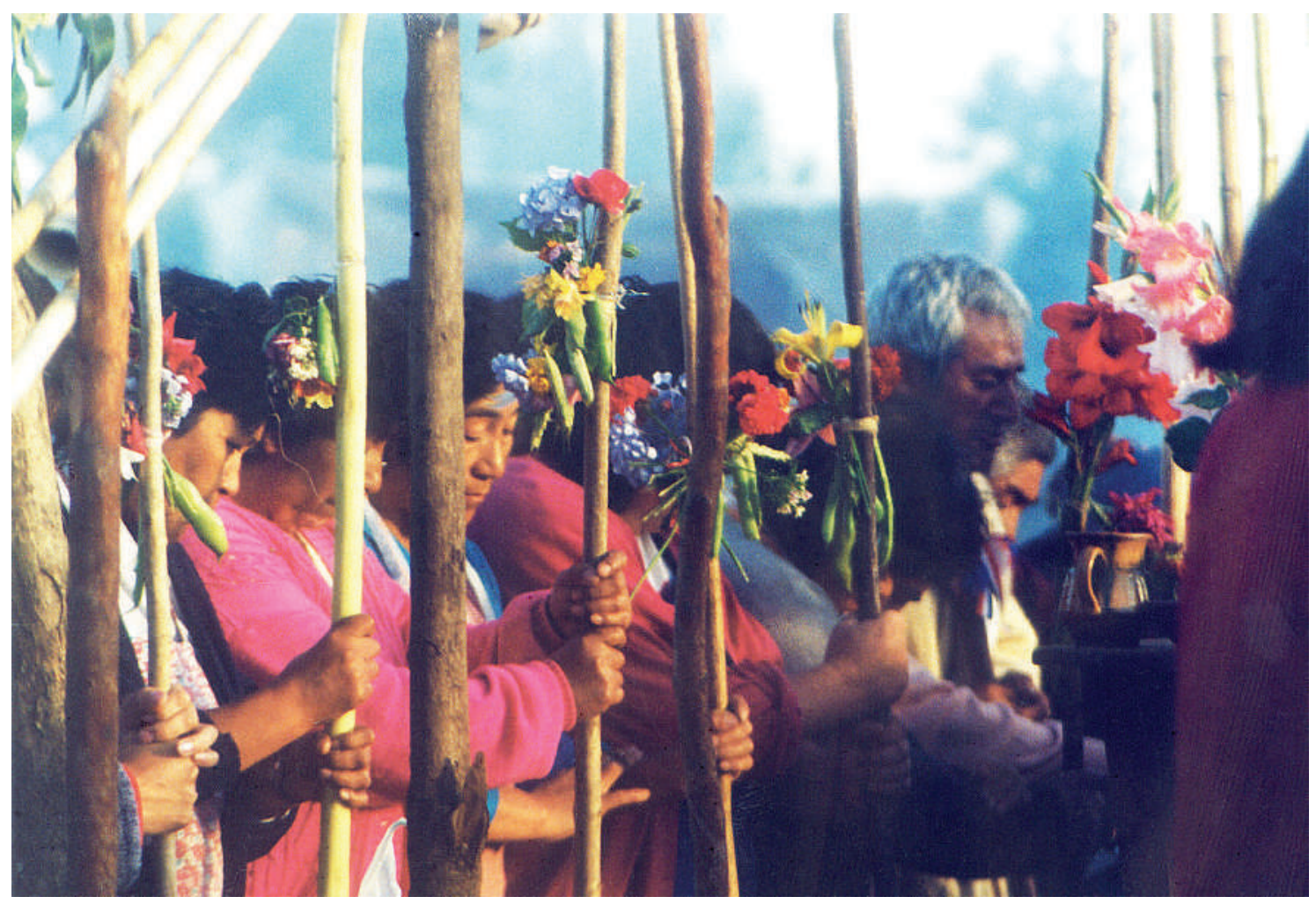

Figura 5. Oraciones mapuches en dirección al naciente durante un ritual de acción de gracias comunitario (fotografía: Rodrigo Moulian, rogativa de Tringlo, Lago Ranco, año 2004). Figure 5. Mapuches praying in the direction of the rising sun during a community thanksgiving ritual (photo: Rodrigo Moulian, Rogativa de Tringlo, Lago Ranco, 2004).

Al respecto, es importante señalar que en la cultura mapuche la expresión de las estructuras dualistas y tetralógicas no se limita a la relación de los términos (dominio social), sino comprende la constitución de los mismos (dominio ontológico). Así, el registro de las oraciones, en ocasiones, atribuye un dimorfismo de género a los astros, propiciados como Antü fucha (sol anciano) y Antu kuse (sol anciana); Küyen fucha (anciano luna) y Küyen kuse (anciana luna) (Faron 1997 [1964], Montecino 1995). También emplean el modelo cuatripartito para la representación de uno de los términos, como en el caso de Meli kuyen, los cuatro dioses de la luna, o Wünelfe, el lucero del amanecer, concebido como una manifestación tetrádica (Grebe et al. 1972). Se verifica aquí la aplicación de un mismo principio de organización cognoscitivo en dos campos clasificatorios, complementarios, siendo el dominio social de uso predominante sobre el ontológico. Como advierten Briones y Olivera (1985), en el primer dominio se identifican entidades independientes, pero estruc- turalmente relacionadas; en el segundo, se distinguen componentes de estas identidades indivisibles entre sí. La concepción del sol y de la luna conformando una familia nuclear, por lo tanto, se encuentra generalizada. En este sistema, a los mayores o ancianos se los representa en nivel superior y se les atribuye una posición social privilegiada respecto de los jóvenes, que son sus hijos. A las figuras masculinas se las sitúa a la derecha y se les asigna una valoración preferente respecto de las femeninas, en cuanto a relevancia y poder.

Si bien, el estatus ontológico de los astros como divinidades se encuentra en la actualidad desperfilado, los mapuches continúan considerando poderosas a estas entidades espirituales. Así, por ejemplo, lo señalan $\mathrm{Cu}-$ raqueo (1989-1990), Pozo y Canio (2014). Como tales, se les propicia en las oraciones y rituales comunitarios y constituyen figuras auxiliares de los y las machi, como se denomina a los chamanes mapuches, quienes invocan preferentemente a la luna, pero, en algunos casos, también al sol (Bacigalupo 1995). 


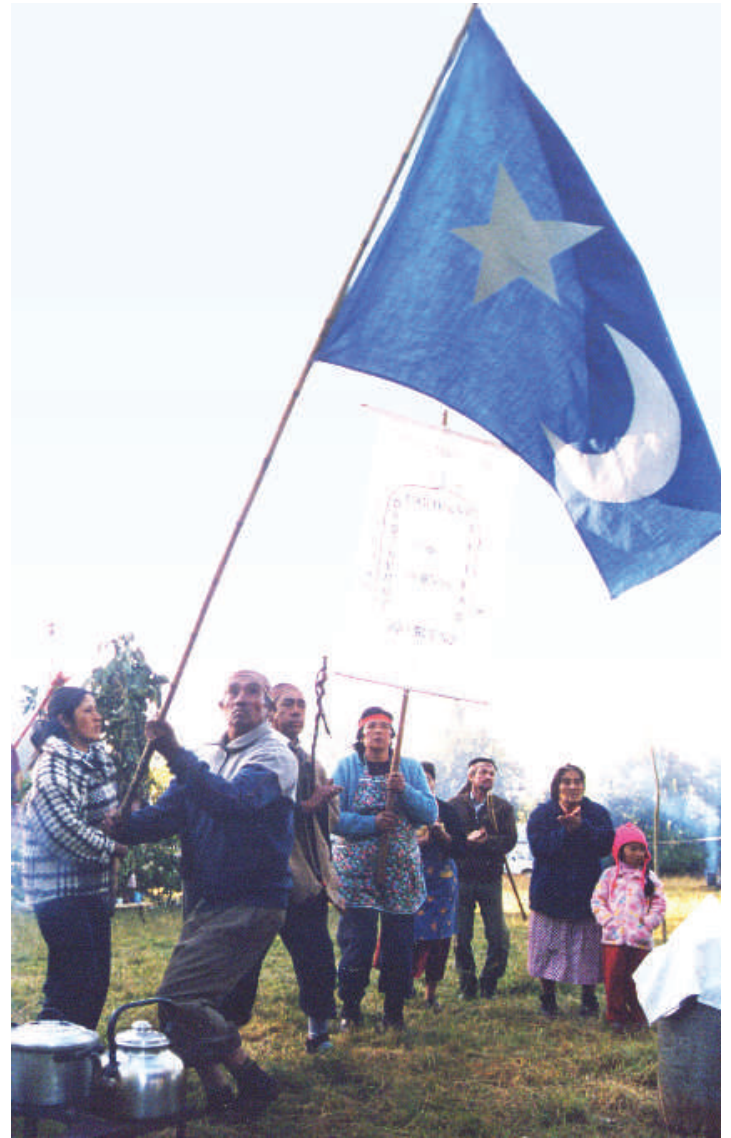

Figura 6. Bandera de una comunidad williche con representaciones de la luna y el lucero del atardecer (fotografía: Rodrigo Moulian, Litrán, Río Bueno, año 2003). Figure 6. A Williche community raises its flag with images of the moon and the evening star (photo: Rodrigo Moulian, Litrán, Río Bueno, 2003).

$\mathrm{Al}$ astro se lo considera responsable de dar luz y calor, de fertilizar la tierra y resguardar la vida. Su valoración es altamente positiva; es masculino, por lo que se lo identifica y representa con la derecha; se lo vincula al Este, a lo alto, al día y al verano (fig. 5).

En contraste, a la luna femenina se la identifica y representa a la izquierda del sol, se la asocia a la noche, a la oscuridad, al invierno. En términos espaciales, se la vincula al Oeste y al mundo subterráneo, ambos con connotaciones negativas pues se asocian a la muerte. No obstante, por lo mismo, se la relaciona con las fuerzas espirituales del otro lado del mundo, donde habitan los ancestros responsables de la renovación de la vida. En cuanto tal, es símbolo de fecundidad. El término aponküyen, luna llena, es comúnmente utilizado como expresión benéfica que contiene la luz, la temperatura, la energía y el vigor necesarios para la buena germinación de las plantas. Es frecuente escuchar en las áreas rurales de la Región de la Araucanía el enunciado "pürapaküyen mew tukungekey fill ketran ka tukukan" ("en luna creciente se siembran las semillas y las hortalizas"), refiriéndose al intervalo que media entre el novilunio y el plenilunio. Es la fase de crecimiento de la luna que culmina con su oposición con el sol, cuando todo su cuerpo brilla, iluminando la tierra. Esta luz nocturna estimula el desarrollo de las plantas con mayor vigor.

La luna se relaciona con el universo femenino. En algunos discursos rituales de iniciación o curación destinados para niñas preadolescentes, aún se hace alusión a küyen como astro iluminado, dueño y símbolo de la fertilidad de las mujeres, en expresiones tales como peküyeni que, en español, corresponde literalmente a "vio la luna", o petu peküyenlay ("todavía no ha visto la luna"). En la visión mapuche, estas expresiones indican la llegada del momento del menstruo en la niña que pasa a la etapa fértil de la iluminación de su vida. El término kuyentun, en tanto, designa el menstruar. De modo concordante, en quechua, la voz killa presenta, entre sus acepciones, el período menstrual de la mujer (Rosat 2009 [1998]: 530).

\section{DISCUSIÓN}

Los datos que hemos expuesto identifican homologías lingüísticas, el correlato en las concepciones sociales y el paralelismo en los patrones de uso del sol y de la luna como indicadores en la organización de los modelos de tiempo y espacio. Si bien estos presentan variantes al interior de y entre los espacios culturales comparados, es evidente la existencia de una matriz de información compartida en este sistema de transformaciones. Su distribución temporal y espacial no debe entenderse como una configuración homogénea, pues siempre será posible documentar excepciones a la regla y modelos alternativos en funcionamiento. No obstante, las formas, representaciones y patrones referidos identifican principios de modelización preferentes. Debe entendérselos como recursos culturales, dispuestos como herramientas para el despliegue de las capacidades humanas, donde la convención alterna con la invención (Wagner 1981, Keisalo-Galván 2011); la memoria y la tradición, con la creación (Lotman \& Upenski 2000) puesta en el contexto de las prácticas culturales. 
La relación del sol y de la luna con el ciclo de la luz, los ritmos circadianos y los procesos estacionales permiten explicar en términos indexales su uso como indicadores en la construcción de los modelos del tiempoespacio. Sus movimientos señalan los pulsos del tiempo y marcan el espacio, con un juego de asociaciones que implican la luz y la oscuridad, el calor y el frío, la lluvia y la sequedad. No ocurre lo mismo con las concepciones sociales de estos 'cuerpos celestes', que se construyen desde una base simbólica. En las culturas inca, aymara y mapuche predomina la representación de ellos como una pareja divina, donde el sol es la figura masculina y la luna su esposa. Entre los incas y mapuches, esta pareja es la base de una familia nuclear cuyos hijos son los luceros del amanecer y atardecer. Esta concepción articula categorías de género, de filiación y religiosas. Ellas se conjugan con las valoraciones que se asignan a las posiciones espaciales, secuencias temporales y ciclos estacionales.

La combinación de las atribuciones de significado de las representaciones sociales y las valoraciones dadas a las coordenadas espacio-temporales configuran 'constelaciones semióticas' en torno a los motivos del sol y de la luna. Con este concepto entendemos el conjunto de las relaciones de significación directamente implicadas, presupuestas o connotadas y asociadas en la interpretación de estas figuras, que dan lugar al uso de las mismas. En las culturas de las áreas centro y sur andinas que hemos referido se advierte un claro correlato en estas constelaciones, que se presentan como opuestas y complementarias.

Las voces inti, antü y su variante anti designan al sol, implican la principal fuente de luz y calor, considerada propiciadora de la vida; presuponen una figura divina superior y masculina, connotan lo positivo, la fertilidad, se asocian al este como punto geográfico, a la derecha en las referencias corporales, a lo alto en el orden espacial, al día en la perspectiva temporal, al verano en términos estacionales, y se usan como indicadores pragmáticos para la organización del comportamiento en el tiempo y el espacio.

Las voces killa, küyen y la variante killen designan a la luna, implican a la principal fuente de luz nocturna, presuponen una deidad superior femenina, se asocian con la izquierda como referencia corporal, con el oeste en términos geográficos, con el mundo subterráneo en el orden espacial, con la noche en la perspectiva temporal, con el invierno en términos estacionales. Su connotación es ambigua en tanto simboliza fecundidad, pero también a las fuerzas del otro lado de la vida.

Los modelos cognitivos que ofrecen estas representaciones informan patrones pragmáticos, cuyo despliegue deja, igualmente, en evidencia, importantes paralelismos. Nos situamos aquí en el dominio de la cosmopraxis (Van Kessel \& Cutipa 1998, De Munter 2016) donde las concepciones constituyen instrumentos organizadores de la acción, proveyendo modelos proxémicos y principios rituales. El correlato de los mismos es especialmente nítido entre los aymaras y mapuches, que diseñan los espacios cúlticos y habitacionales en dirección al este. En tanto, sus movimientos se disponen desde la derecha a la izquierda en un patrón que se expresa en las danzas, el desplazamiento por los espacios sagrados, la distribución de bebidas, alimentos y saludos.

Estas pautas de acción muestran las mismas estructuras de sentido. El tejido cultural de las mismas se hace evidente cuando se contrastan con otras constelaciones semióticas que se articulan en torno a los mismos motivos. En la Amazonía, por ejemplo, se encuentra ampliamente extendida la concepción del sol y de la luna como gemelos masculinos (Blixen 2013) que comparten o compiten por mujeres. En este modelo se diluye el sistema de distinciones polares de género, con sus relaciones contrastantes y complementarias, que veíamos en el caso andino. Variantes del mito de los mellizos astrales se encuentran registradas entre los tupi-guaraní de Brasil (Métraux 1928), incluyendo los chirihuanos del chaco boliviano (Métraux 1932), entre los kuikoró de lengua caribe del parque Xingu, en Brasil (Fausto 2012), y los amuesha, de lengua pano del este de Perú (Kühne 1967). Para los wara, grupo de lengua arawak, las relaciones incestuosas homosexuales entre ellos son causa de los eclipses (Penteao 1983). En contraste, los ticuna del alto Solimoes, entre Brasil, Colombia y Perú, suscriben una mitología dualista en términos de las categorías de género, pero identifican al sol como mujer (Faulhaber 2015). Por lo mismo, Lehmann-Nitsche (1919) advertía que, en el marco de la diversidad de representaciones del sol y de la luna presentes en la mitología sudamericana, la constante andina informa una vincularidad cultural.

En nuestro caso de estudio, el correlato en las constelaciones semióticas se ve refrendado por homologías en las formas lingüísticas del quechua y mapudungun que designan al sol y a la luna. Esta afinidad no se puede explicar como resultado de la expansión del quechua 
imperial a la Araucanía. La influencia inca en la zona central de Chile ha sido datada por termoluminiscencia de piezas cerámicas hacia 1390 DC (Cornejo 2014). Si las voces antü y küyen fuesen quechuismos, habría un registro de los términos originarios del mapudungun que nombra a estos astros, lo que no ha ocurrido. Por lo mismo, resulta sugerente la hipótesis del puquina, la que se considera fue la lengua de la cultura Tiwanaku y de sus precedentes en el área del Titicaca. Cerrón-Palomino (2013a) plantea que el puquina es la lengua secreta de los 'orejones', la casta dominante del incario, que habría procedido del lago altiplánico. Como argumenta este autor y lo registra De la Grasserie (1894), inti es parte del repertorio léxico puquina. Lo mismo ha señalado Aguiló (2000) sobre la voz illa, que es la raíz del término killa. Dillehay et al. (2007) muestran, al respecto, que a partir del año 1000 de nuestra era se inicia un largo período de sequía en el área central andina. Esta crisis medioambiental prolongada coincide con el abandono de Tiwanaku y el aumento de la complejidad social de la Araucanía, marcada por la modelación de paisajes monumentales y el desarrollo de la agricultura intensiva. Estos datos presuponen formas de organización social ampliada. Los antecedentes contextuales invitan a explicar esta transformación social como producto de las presiones migratorias ante las condiciones climáticas.

\section{CONCLUSIONES}

Las homologías lingüísticas, el correlato en las constelaciones semióticas, el paralelismo de los patrones proxémicos y temporales muestran una tradición cultural compartida en las áreas centro, centro-sur y sur andinas, configurada en torno a los motivos del sol y de la luna. Estos componentes no bastan para postular la unidad histórico-cultural del territorio que registra este correlato, pero los datos constituyen nítidos indicadores de relaciones interculturales que comprometen vínculos sociales.

Al respecto, debe tenerse en cuenta que solo la concordancia de los modelos de tiempo-espacio se puede explicar en términos indexales, es decir, sobre la base de la observación de procesos naturales. No sucede lo mismo con la semejanza en las formas lingüísticas y el correlato de las concepciones sociales de los astros, que tienen un carácter convencional, es decir, se producen socialmente. La representación de estos cuerpos celestes como una familia divina, donde el sol asume los roles de varón, esposo y padre; la luna de mujer, esposa y madre, y los luceros de hijos, implica concepciones de género, teológicas y de filiación social que se articulan sobre series de relaciones de significación implicadas, presupuestas, asociadas y connotadas de manera coincidente. Estas representaciones ocupan, además, un papel preeminente en los sistemas religiosos y cosmovisionarios de las culturas del área. Ellas, por ejemplo, contrastan las concepciones de los mismos astros como hermanos gemelos, predominante en el área amazónica. Son el resultado de procesos de elaboración cultural cuyo correlato en el área andina muestra una tradición compartida, que no se produce de modo natural sino como resultado de relaciones sociales subyacentes.

En nuestro caso de estudio, ello no se puede explicar como el efecto de la expansión del Tawantinsuyo en el área centro-sur de Chile. De ser este el caso, se esperaría hubieran quedado en el repertorio léxico del mapudungun las voces originarias que nombraban a los astros, lo que no sucede. Una hipótesis alternativa, sustentada por datos contextuales lingüísticos, etnohistóricos y arqueológicos, es la posible filiación puquina de estas voces. Ello podría ser resultado de interacciones que se producen a partir del colapso de Tiwanaku, pero también de un período anterior, considerando los antecedentes históricos y culturales de esta lengua. En cualquier alternativa, las homologías lingüísticas y el correlato en las constelaciones semióticas informan la profundidad histórica de las relaciones interculturales en las áreas centro, centro-sur y sur andinas que han dado lugar a este sistema de representaciones compartidas.

Agradecimientos a FONDECYT por el financiamiento del proyecto 1160388: "Translingüística, supralingüística e interculturalidad: un estudio de casos de correlaciones en constelaciones semióticas centro y sur andinas indicadoras de cotradición" que ha hecho posible nuestra investigación. A Milton Eyzaguirre Morales, antropólogo, encargado de la Unidad de Extensión del MUSEF, en La Paz, por su disposición a atender nuestras dudas. A Pedro Galindo por su contribución a la revisión del texto original. 


\section{REFERENCIAS}

Abercrombie, T. 1998. Pathways of memory and power. Madison: The University of Wisconsin Press.

Adán L., Mera, R., Navarro, X., Campbell, R., Quiroz, D. \& SÁNCHEZ, M. 2016. Historia prehispánica en la región centro-sur de Chile: cazadores recolectores holocénicos y comunidades alfareras (ca. 10000 años AC a 1550 años DC). En Prehistoria en Chile desde sus primeros habitantes hasta los incas, Falabella, F. et al. Eds., pp. 401-441. Santiago: Editorial Universitaria-Sociedad Chilena de Arqueología.

Aguiló, F. 2000. El idioma del pueblo puquina: un enigma que va aclarándose. Quito: Fondo Ecuatoriano Populorum Progressio-Universidad Intercultural de las Nacionalidades y Pueblos Indígenas.

Almonte, C. 1975 [1813]. Respuestas al interrogatorio enviado al cura de Andahua (partido de Condesuyo) sobre las costumbres y organizaciones de los pobladores de su jurisdicción. Allpanchis 8: 54-64. Cusco.

Arguedas, J. M. 2006 [1958]. Los ríos profundos. Caracas: Perro de Lana.

Arnold, D., Jiménez, D. \& YAPItA, J. 1998. Hacia un orden andino de las cosas. La Paz: Hisbol-ILCA.

Augusta, F. \& FraunhäusL, S. 1910. Lecturas araucanas. Valdivia: Imprenta de la Prefectura Apostólica.

Augusta, F. 1916. Diccionario araucano-español y españolaraucano. Tomo primero. Santiago: Imprenta Universitaria.

Bacigalupo, A. 1988. Definición, evolución e interrelaciones de tres conceptos mapuches: Pillan, Ngüenenchen y Weku$f u$. Tesis para optar al grado de Licenciado en Historia. Instituto de Historia, Pontifica Universidad Católica de Chile, Santiago.

BACIgAlupo, A. M. 1995. Imágenes de diversidad y consenso: la cosmovisión mapuche a través de tres machis. Aisthesis 28: 120-141. Santiago: Instituto de Estética de la Pontificia Universidad Católica.

Bacigalupo, A. M. 1995-1996. Ngünechen, el concepto de Dios mapuche. Historia 29: 43-68. Santiago.

BAHAMONDES, F. 2009. La cerámica prehispánica tardía de la Araucanía septentrional: el complejo arqueológico El Vergel y su relación con la hipótesis del proceso de andinización. Memoria para optar al título de Arqueólogo. Departamento de Antropología, Facultad de Ciencias Sociales, Universidad de Chile, Santiago.

BAndelier, A. 1910. The island of Titicaca and Coati. Nueva York: Hispanic Society of America.

BARNES, M. 1986. Representations of the cosmos: a comparison of the church of San Cristóbal de Pampachiri with the Coricancha drawing of Santacruz Pachacuti Yamqui Salcamaygua. En Perspectives on Andean prehistory and protohistory: papers from the Third Annual Northeast Conference on Andean Archaeology and Ethnohistory, pp. 145-157. Ithaca: Cornell University Press.
Barros, D. 1884. Historia Jeneral de Chile. Tomo 1. Santiago: Rafael Jover Editor.

Bauer, B. \& Dearborn, D. 1998. Astronomía e imperio en los Andes. Cusco: Centro de Estudios Regionales Andinos Bartolomé de Las Casas.

Bennett, W. 1948. The Peruvian co-tradition. Memoirs of the Society of American Archaeology 4: 1-7. Washington.

Bertonio, L. 2015 [1612]. Transcripción del vocabulario de la lengua aymara. La Paz: Instituto de Lenguas AndinasAmazónicas.

Blixen, O. 2013. La luz y las tinieblas. El día y la noche en la mitología sudamericana. Buenos Aires: CIAfIC.

Bouysse-CAssagne, T. 1987. La identidad aymara: Aproximación histórica (siglo XV, siglo XVI). La Paz: Hisbol-IFEA.

Briones, C. \& Olivera, M. 1985. Che kimin: un abordaje a la cosmo-lógica mapuche. Runa 15: 43-81. Buenos Aires.

CÁCERES, E. 2016. Sistema económico indígena andino. Quito: Abya-Yala.

Cañas, O. 1910. Estudio de la lengua veliche. En Trabajos del Cuarto Congreso Científico ( $1^{\circ}$ Panamericano) [celebrado en Santiago de Chile del 25 de diciembre de 1908 al 5 de enero de 1909], volumen 20, pp. 143-330. Santiago: Imprenta Barcelona.

Carrasco, A. \& Gavilán, V. 2009. Representaciones del cuerpo, sexo y género entre los aymara del norte de Chile. Chungara 41 (1): 83-100. Arica.

Castro, V. \& VArela, V. 2004. De cómo camina el sol durante junio, de lo que se ve en el cielo y de lo que se comenta y practica en la tierra. Oralidad y rituales en la subregión Río Salado, norte de Chile. En Etno y arqueoastronomía en las Américas. M. Boccas, J. Broda y G. Pereira, Eds. Santiago: Memorias del simposio ARQ- 13 del $51^{\circ}$ Congreso Internacional de Americanistas.

Celestino, O. 1997. Transformaciones religiosas en los Andes peruanos, 1: ciclos míticos y rituales. Gazeta de Antropología 13: 1-19. Granada.

Cerrón-Palomino, R. 2013a. Las lenguas de los incas. Frankfurt: Peter Lang.

Cerrón-Palomino, R. 2013b. Cuando los mitos tienen fondo de historicidad: El origen lacustre de los Incas primordiales. Revista Brasileira de Lingüística Antropológica 5 (1): 31-43. Brasilia.

Cerrón-Palomino, R. 2016. El lenguaje como hermenéutica en la comprensión del pasado: a propósito del puquina en la génesis del imperio incaico. Diálogo Andino 49: 11-27. Arica.

Сово, В. 1892 [1653]. Historia del Nuevo Mundo. Tomo III. Sevilla: Imprenta de E. Rasco.

Cook, G. \& Doyle, M. 1978. Del culto solar a la clandestinidad de Inti Punchao. Historia y Cultura 11: 51-73. Lima.

Cornejo, L. 2014. Sobre la cronología del inicio de la imposición cuzqueña en Chile. Estudios Atacameños 47: 101-116. San Pedro de Atacama. 
Cruz, J., Cortés J. \& Yufla, C. 2013 Ms. El universo de nuestros abuelos: Proyecto de investigación etnoastronómico de Atacama. San Pedro de Atacama: ilam-alma.

Curaqueo, D. 1989-1990. Creencias religiosas mapuche: Revisión crítica de las interpretaciones vigentes. Revista Chilena de Antropología 8: 27-36. Santiago.

D’Ans, B. \& Aguirre, M. 2016. Límites geográfico-astronómicos del Tahuantinsuyo. Tradición 13: 17-24. Lima.

De Munter, K. 2016. Ontología relacional y cosmopraxis, desde los Andes: visitar y conmemorar entre familias aymara. Chungará 48 (4): 629-644. Arica.

Dearborn, D. \& Schreiber, K. 1989. Houses of the rising sun. En Time and the calendars in the inca empire, M. Ziólkowski \& R. Sadowski, Eds., pp 49-74. Oxford: BAR International Series 479.

Descola, P. 2012. Más allá de la cultura y la naturaleza. Buenos Aires: Amorrortu.

Díaz-Fernández, A. 1992. Contacto del mapudungun con dos lenguas principales del Tawantinsuyo: el quechua y el yunga. Actas de la Lengua y Literatura Mapuche 5: 193-201. Temuco.

Dillehay, T. \& Gordon, A. 1998. La actividad prehispánica de los incas y su influencia en la Araucanía. En Las fronteras del Estado Inca, T. Dillehay \& P. Netherly, Comps. Quito: Fundación Alexander Humboldt y Editorial Abya-Yala.

Dillehay, T. 1990. Araucanía: presente y pasado. Santiago: Andrés Bello.

Dillehay, T. 2007. Monuments, empires, and resistance: the Araucanian polity and ritual narratives. New York: Cambridge University Press.

Dillehay, T., Pino, M., Bonzani, R., Silva, C., Wallner, J. \& Le Quesne, C. 2007. Cultivated wetlands and emerging complexity in south-central Chile and long distance effects of climate change. Antiquity 81: 949-960. Durham.

Douglas, M. 1996 [1970]. Natural Symbols: explorations in cosmology. London: Routledge.

Eco, U., 1992 [1990]. Los límites de la interpretación. Barcelona: Lumen.

ENGLERT, S. 1934. Los elementos derivados del aymará y el quichua en el idioma araucano. Anales de la Facultad de Filosofía y Educación 1 (1): 5-27. Santiago.

ERIZE, E. 1960. Diccionario comentado mapuche-español. Buenos Aires: Universidad Nacional del Sur.

EspinozA, W. 1987. Los incas: economía, sociedad y estado en la era del Tahuantinsuyo. Lima: Amaru Editores.

Estermann, J. 1998. Filosofía andina: estudio intercultural de la sabiduría autóctona andina. Quito: Abya-Yala.

FARON, L. 1997 [1964]. Antüpaiñamko: moral y ritual mapuche. Santiago: Mundo-Nuevo Mundo-Museo Chileno de Arte Precolombino.

Faulhaber, P. 2015. Ticuna astronomy, mythology and cosmovision. En Handbook of archaeoastronomy and ethnoastronomy, C.L.N. Ruggles, Ed., pp. 953-958. Nueva York: Springer.
Fausto, C. 2012. Sangue de lua: reflexôes sobre espíritos e eclipses. Journal de la Société des Américanistes 98 (1): 63-80. París.

Fuenzalida, F. 1979. El Cristo pagano de los Andes: una cuestión de identidad y otra sobre las eras solares. Debates en Sociología 4: 1-10. Lima.

GARcía, J. 2013. El culto andino al sol: religiosidad y simbolismo solar en las culturas rurales. En Iglesias y fiestas en el altiplano de La Paz y Oruro: Aproximaciones multidisciplinarias, R. Molina, Coord., pp. 109-115. La Paz: Musef.

Garcilaso de la Vega, I. 2012 [1609]. Comentarios reales de los incas. Arequipa: El Lector.

GhezzI, I. \& Ruggles, C. 2006. Las trece torres de Chankillo: arqueoastronomía y organización social en el primer observatorio solar de América. Boletín de Arqueología Pontificia Universidad Católica del Perú. Lima.

GonzÁlez de Holguín, D. 2007 [1608]. Vocabvlario de la lengva general de todo el Perv, llamada lengua qquichua, o lengva del Inca, edición digitalizada por el Grupo Runasimipi Quespisqa Software [online]. <http://www.illa-a. org/cd/diccionarios/VocabvlarioQqichuaDeHolguin.pdf> [Consultado 19 septiembre 2018].

Grasserie, R. DE LA,1894. Langue puquina. Leipzig: Koehler.

GREBE, M. 1990. La concepción del tiempo en la cultura aymara: representaciones icónicas, cognición y simbolismo. Revista Chilena de Antropología 9: 63-81. Santiago.

Grebe, M. 1995-1996. Continuidad y cambio en las representaciones icónicas: significados simbólicos en el mundo sur andino. Revista Chilena de Antropología 13: 137-154. Santiago.

Grebe, M. 1996. Patrones de continuidad en el mundo sur andino: creencias y estudios vinculados a los astros y los espíritus de la naturaleza. En Cosmovisión Andina, pp. 205-220. La Paz: Centro de Cultura, Arquitectura y Arte Taipinquiri.

Grebe, M. 2002. Los mapuches de Chile en el contexto del mundo andino: algunas perspectivas interculturales. Lengua y Literatura Mapuche 10: 23-34. Temuco.

Grebe, M., Pacheco, S. \& Segura, J. 1972. Cosmovisión mapuche. Cuadernos de la Realidad Nacional. Santiago.

Guaman Poma de Ayala, F. 1980 [1615]. Nueva Corónica y Buen Gobierno. Caracas: Ayacucho.

Guevara, T. 1911. Folklore araucano. Santiago: Cervantes.

Gundermann, H. 1981. Análisis estructural de los ritos mapuche: nguillatún y pïntevún. Tesis para optar al grado de licenciado en Antropología Social, Facultad de Ciencias Sociales, Universidad de Chile, Santiago.

Havestadt, B. 1883 [1777]. Chilidúnǵu sive tractatus linguae chilensis. Volumen II, Julio Platzmann, Ed. Leipzig: в. G. Teubner.

Ibarra, E. 1982. Ciencia en Tihuanaku y el incario. La Paz: Amigos del Libro.

Instituto Nacional de Cultura. 1979. Críticas y perspectivas de la arqueología andina. Lima: Proyecto Regional de Patrimonio Cultural Andino UNESCO/PNUD. 
Keisalo-Galván, M. 2011. Cosmic clowns: convention, invention, and inversion in the Yaqui easter ritual. Helsinki: University of Helsinki.

Koessler-ILG, B. 1996 [1954]. Cuentan los araucanos. Buenos. Aires: Nuevo Mundo.

Koessler-Ilg, B. 2006. Cuenta el pueblo mapuche. Volumen II: Mitos y leyendas. Santiago: Mare Nostrum.

KüHNE, H. 1967. El jaguar en el mito de los héroes mellizos (sol y luna), tribu amuesha (Perú oriental). Runa 10 (1-2): 311-318. Buenos Aires.

LAтснам, R. 1924. La organización social y las creencias religiosas de los antiguos araucanos. Santiago: Cervantes.

LehmanN-Nitsche, R. 1919. El diluvio según los araucanos de la Pampa. Revista del Museo de La Plata 26 (segunda Serie): 28-62. La Plata.

Lotman, I. \& Upenski, A. 2000. Sobre el mecanismo semiótico de la cultura. En La Semiósfera III, pp. 168-193. Madrid: Cátedra.

LUMBRERAs, L. 1969. El área cotradicional meridional andina. Boletín del Museo Nacional de Historia Natural 30: 65-79. Santiago.

Lumbreras, L. 1981. Arqueología de América andina. Lima: Milla Batres.

MAGAÑA, E. 2006. Astronomía de algunas poblaciones quechuaaymara del Loa Superior, norte de Chile. Boletín del Museo Chileno de Arte Precolombino 11 (2): 51-56. Santiago.

Malville, M. 2014. Pre-inca astronomy in Perú. En Handbook of archaeostronomy and ethnoastronomy, C. Ruggles, Ed., pp. 795-804. Berlín: Springer.

Mamani, M. 2012. El discurso religioso en el aymara de Bertonio y el discurso ritual en el aymara de la provincia de Camacho. Ciencia y Cultura 28: 237-261. La Paz.

Marileo, A. 1995. Mundo mapuche. En Medicinas y culturas en la Araucanía, L. Citarela, comp., pp. 91-107. Santiago: Sudamericana.

Matos, R. 1994. Pumpu: centro administrativo inka de la puna de Junín. Lima: Horizonte.

MéTraux, A. 1928. La religion des Tupinamba et ses rapports avec celle des autres tribus tupi-guarani. París: Ernest Leroux.

Métraux, A. 1932. Mitos y cuentos de los indios chiriguanos. Revista de La Plata 33: 119-184. La Plata.

Mishkin, B. 1940. Cosmological ideas among the Indians of Southern Andes. Journal of American Folklore 53 (210): 225-241. Illinois.

Moesbach, E. 1980. Diccionario español mapuche. Buenos Aires: Siringa Libros.

Montecino, S. 1995. Sol viejo, sol vieja: lo femenino en las representaciones mapuches. Santiago: SERNAM.

MоттA, E. 2011. Pacha: visión andina del espacio tiempo en la perspectiva del pensamiento seminal. Tesis para optar al grado de Doctor en Filosofía. Universidad Nacional Mayor de San Marcos, Lima.

Moulian, R. \& EsPinOZA, P. 2015. La impronta andina entre los kamaskos del Wenuleufu. Atenea 512: 211-230. Concepción.
Moulian, R. \& Valdés, C. 2001. Abuelito Huenteao: mito $y$ ritual. Documental etnográfico del peregrinaje de una comunidad a la roca de Pucatrihue. Valdivia: Fondo Nacional del Desarrollo de la Cultura y las Artes-Universidad Austral de Chile.

Moulian, R. 2005. Tiempo de lepün: una etnografía visual del ngillatun williche. Valdivia: Programa Orígenes-Universidad Austral de Chile.

Moulian, R. 2008. Ngen rüpu/ el camino del Ngen: un trabajo de arqueología de los símbolos y etnografía multimedia. Valdivia: Fondo Nacional del Desarrollo de la Cultura y Las Artes-Universidad Austral de Chile.

Moulian, R. 2015 Ms. Translingüística, supralingüística e interculturalidad: un estudio de casos de correlaciones en constelaciones semióticas centro y sur andinas. Formulación del Proyecto Fondecyt 1160388.

Moulian, R., 2012. Metamorfosis ritual: desde el nguillatun al culto pentecostal. Valdivia: Kultrún \& Universidad Austral de Chile.

Moulian, R., Catrileo, M. \& LANdeo, P. 2015. Afines quechua en el vocabulario mapuche de Luis de Valdivia. Revista de Lingüística Teórica y Aplicada 53 (2): 73-96. Concepción.

MoyAno, R. 2014. Astronomical observation on Inca ushnus in southern Andes. En Inca Sacred Space: Landscape, Site and Symbol in the Andes, F. Meddens, C. McEwan, K. Willis \& N. Branch, Eds., pp. 187-196. London: Archetype Publications.

Murúa, M. 1922 [1590]. Historia de los incas, reyes del Perú. Lima: Sanmartí.

MurúA, M. 2004 [1590]. Historia y genealogía de los reyes incas del Perú. Madrid: Testimonio Compañía Editorial.

NúÑez del Prado, O., Flores Ochoa, J., NúÑez del Prado, J., Castillo, M., Barreda, L., Cohen, J., Escobar, M., Champi, F. \& Getzelz, J. 2005 [1955]. Q'ero, el último ayllu inka: Homenaje a Óscar Núñez del Prado y a la expedición científica de la UNSAAC a la nación Q'ero en 1955. Lima: Universidad Nacional Mayor de San Marcos.

NúÑEZ, R. \& CoRneJo, C. 2012. Facing the sunrise: cultural worldview underlying intrinsic-based encoding of absolute frames of reference in Aymara. Cognitive Science 36 (6): 965-991. Stanford.

ORÉ, J. 1607. Ritvale sev Manvuale Pervanvm. Neapoli: Jacobum Carlinum et Constantinum Vitalem.

OrTiz, E. 2012. Los incas y el sol: métodos de observación solar y calendarios incaicos. Revista Española de Antropología Americana 42 (1): 127-143. Madrid.

PATrón, P. 1912. Influencia del dominio peruano en Chile. En Trabajos del Cuarto Congreso Científico, Sección Ciencias Naturales, Antropológicas y Etnológicas, Vol. XVII: 101-180. Santiago: Barcelona.

Peirce, C. S. 1965. Elements of logic. En Collected papers of Sanders Charles Peirce: Volume I, Principles of philosophy and Volume 2, Elements of Logic, C. Hartshorne \& P. Weiss, Eds. Cambridge: The Belknap Press. 
Peirce, C. S. 1974. La ciencia de la semiótica. Buenos Aires: Nueva Visión.

Penteao, V. 1983. Um eclipse do sol na aldeia Waurá. Journal de la Société des Américanistes 69: 149-167. París.

Pinasco, A. 2007. Con el sol, la luna y las estrellas: arqueoastronomía en Pachakamaq. Lima: Instituto Peruano de Etnociencias.

PINo, J. L. 2004. Observatorios y alineamientos astronómicos en el Tampu Inka de Huánuco Pampa. Arqueología y Sociedad 15: 173-190. Lima.

PlatT, T. 1976. Espejos y maíz: temas de estructura simbólica andina. La Paz: Centro de Investigación y Promoción del Campesinado.

Pozo, G. \& CANio, M. 2014. Wenumapu: astronomía y cosmología mapuche. Santiago: Ocho Libros.

Ramos, D. 2013. Catequil, el ídolo norteño. Revista Científica In Crescendo 4 (2): 285-292. Chimbote.

Riveros, F. 1996. Arquitectura de Tiwanaku: astronomía y calendarios. La Paz: Iv Bienal Boliviana de Arquitectura.

Rosat, A. 2009 [1998]. Diccionario enciclopédico quechua castellano del mundo andino. Cochabamba: Verbo Divino.

SAnHuEza, C. 2005. Espacio y tiempo en los límites del mundo: los incas en el despoblado de Atacama. Boletín del Museo Chileno de Arte Precolombino 10: 2 (51-77). Santiago.

Sanhueza, C. 2017. Las saywas del inka en el desierto de Atacama. ¿Una inscripción del calendario en el Qapaq Nam? Boletín del Museo Chileno de Arte Precolombino 22 (2): 133-152. Santiago.

Santa Cruz Pachacuti, J. 1879 [1613]. Relación de antigüedades del reyno del Pirú. En Tres Relaciones de Antigüedades Peruanas, M. Jiménez de Espada, Ed. Madrid: Imprenta y Fundición de M. Tello.

SilverblatT, I. 1987. Moon, sun and witches: gender ideologies and class in Inca and colonial Peru. Princeton: Princeton University Press.

Silverman-Proust, G. 1986. Cuatro motivos inti de Q'ero. Boletín de Lima 43: 61-76. Lima.

Silverman-Proust, G. 1988. Tawa inti qocha, símbolo de la cosmología andina: concepción Q’ero del espacio. Anthropologica 6 (6): 9-42. Lima.

Steele, R. \& Allen, J. 2004. Handbook of Inca mythology. Santa Barbara: ABC-CLIO.

Stehberg, R. 1976. La fortaleza de Chena y su relación con la ocupación incaica de Chile central. Publicación Ocasional del Museo Nacional de Historia Natural 23: 3-37. Santiago.

Torero, A. 1972. Lingüística e historia de la sociedad andina. En El reto del multilingüismo en el Perú, A. Escobar, Ed., pp. 51-106. Lima: Instituto de Estudios Peruanos.

Torero, A. 1987. Lenguas y pueblos altiplánicos en torno al siglo Xvi. Revista Andina 10: 329-405. Cusco.

Torero, A. 2005. Idiomas de los Andes: lingüística e historia. Lima: Horizonte.

Tsснорік, H. 2015 [1951]. Magia en Chucuito. Puno: Universidad Nacional de Puno.
URTON, G. 2006. El cruce de rumbos de la tierra y el cielo. Cusco: Centro Bartolomé de Las Casas.

VAldivia, L. 1887 [1606]. Arte y gramática general de la lengva que corre en todo el reyno de Chile con vn confessionario y vocabvlario, J. Platzmann, Ed. Leipzig: B. G. Teubner.

VAleriano, E. 2002. Calendario lunisolar andino aymaraquechua. La Paz: Editorial Eschotel.

VAN DEN BERG, J. 1989. 'La tierra no da así no más': los ritos agrícolas en la religión de los Aymara-cristianos de los Andes. Amsterdam: Centrum voor Studie en Documentatie van Latijns Amerika (CEDLA).

van Kessel, J. \& Cutipa, G. 1998. El marani de Chipukuni. Iquique: IECTA-CIDSA.

van Kessel, J. 1980a. Holocausto al progreso: los aymara de Tarapacá. Amsterdam: Centrum voor Studie en Documentatie van Latijns Amerika (CEDLA).

VAN KESSEL, J. 1980b. Ecología y orientación: problemas de la identidad cultural de los aymaras chilenos contemporáneos. Chungara 6: 137-144. Arica.

van Kessel, J. 1982. Danzas y estructuras sociales en los Andes. Cusco: Instituto de Pastoral Andina.

WAAG, E. M. 1975. El ser supremo de los mapuche neuquinos. Relaciones de la Sociedad Argentina de Antropología 9: 147-154. Buenos Aires.

WAGNER, R. 1981. The invention of culture. Chicago: University of Chicago Press.

WinZeler, R. 2012. Anthropology and religion: what we know, think, and question. Plymouth: Altamira Press.

WissLer, C. 1917. The American Indian. Nueva York: McMurtrie.

Zıólkowski, M. \&. R. SADowski. 1992. La arqueoastronomía en la investigación de las culturas andinas. Pendoneros 9. Otavalo.

ZıóLKowski, M. 1989. El calendario metropolitano inca. En Time and the calendars in the Inca Empire, M. Ziólkowski \& R. Sadowski, Eds., pp. 129-166. Oxford: BAR International Series 479.

Zıólkowski, M. 2015. Pachap vnancha: el calendario metropolitano del Estado inca. Arequipa: El Lector.

Zuidema, T. 1982a. Catachillay: the role of the Pleiades and of the Southern Cross and $\alpha$ and $\beta$ Centauri in the calendar of the Incas. Annals of the New York Academy of Sciences 385: 203-289. Nueva York.

Zuidema, T. 1982b. The sidereal lunar calendar of the Incas. En Archeoastronomy in the New World, A. F. Aveni, Ed., pp. 59-107. Oxford: Cambridge University Press.

Zuidema, T. 2010. El calendario inca: tiempo y espacio en la organización ritual del Cuzco. La idea del pasado. Lima: Fondo Editorial del Congreso del Perú-Pontificia Universidad Católica del Perú. 